\title{
Asymmetric Inter- and Intramolecular Cyclopropanation of Alkenes Catalyzed by Chiral Ruthenium Porphyrins. Synthesis and Crystal Structure of a Chiral Metalloporphyrin Carbene Complex
}

\author{
Chi-Ming Che, ${ }^{*}$ Jie-Sheng Huang, Fu-Wa Lee, Yan Li, Tat-Shing Lai, Hoi-Lun Kwong, ${ }^{\dagger}$ \\ Pang-Fei Teng, ${ }^{\dagger}$ Wing-Sze Lee, ${ }^{\dagger}$ Wai-Cheung Lo, Shie-Ming Peng, ${ }^{\dagger}$ and Zhong-Yuan Zhou ${ }^{\S}$
}

Contribution from the Department of Chemistry, The University of Hong Kong, Pokfulam Road, Hong Kong, Shanghai-Hong Kong Joint Laboratory on Chemical Synthesis, Shanghai Institute of Organic Chemistry, Shanghai, China, Department of Biology and Chemistry, City University of Hong Kong, Tat Chee Avenue, Kowloon Tong, Hong Kong, Department of Chemistry, National Taiwan University, Taipei, Taiwan, and Department of Applied Biology and Chemical Technology, The Hong Kong Polytechnic University, Hung Hom, Kowloon, Hong Kong

Received April 24, 2000

\begin{abstract}
Extensive investigations of asymmetric intermolecular cyclopropanation of terminal alkenes with diazoacetates catalyzed by ruthenium porphyrin $\left[\mathrm{Ru}\left(\mathrm{P}^{*}\right)(\mathrm{CO})(\mathrm{EtOH})\right]\left(\mathbf{1}, \mathrm{H}_{2} \mathrm{P}^{*}=5,10,15,20\right.$-tetrakis$\{(1 S, 4 R, 5 R, 8 S)-1,2,3,4,5,6,7,8$-octahydro-1,4:5,8-dimethanoanthracene-9-yl $\}$ porphyrin) and the application of catalyst 1 to asymmetric intramolecular cyclopropanation of allylic or homoallylic diazoacetates are described. The intermolecular cyclopropanation of styrene and its derivatives with ethyl diazoacetate afforded the corresponding cyclopropyl esters in up to $98 \%$ ee with high trans/cis ratios of up to 36 and extremely high catalyst turnovers of up to $1.1 \times 10^{4}$. Examination of the effects of temperature, diazoacetate, solvent, and substituent in the intermolecular cyclopropanation reveals that (i) both enantioselectivity and trans selectivity increase with decreasing temperature, (ii) sterically encumbered diazoacetates $\mathrm{N}_{2} \mathrm{CHCO}_{2} \mathrm{R}$, such as $\mathrm{R}=\mathrm{Bu}^{\mathrm{t}}$, and donor solvents, such as diethyl ether and tetrahydrofuran, are beneficial to the trans selectivity, and (iii) electron-donating para substituents on styrene accelerate the cyclopropanations, with the $\log \left(k_{\mathrm{X}} / k_{\mathrm{H}}\right)$ vs $\sigma^{+}$plot for para-substituted styrenes $p-\mathrm{X}-\mathrm{C}_{6} \mathrm{H}_{4} \mathrm{CH}=\mathrm{CH}_{2}\left(\mathrm{X}=\mathrm{MeO}, \mathrm{Me}, \mathrm{Cl}, \mathrm{CF}_{3}\right)$ exhibiting good linearity with a small negative $\rho^{+}$value of $-0.44 \pm 0.09$. In the case of intramolecular cyclopropanation, complex 1 promoted the decomposition of a series of allylic diazoacetates to form the cyclopropyl lactones in up to $85 \%$ ee, contributing the first efficient metalloporphyrin catalyst for an asymmetric intramolecular cyclopropanation. Both the inter- and intramolecular cyclopropanations were proposed to proceed via a reactive chiral ruthenium carbene intermediate. The enantioselectivities in these processes were rationalized on the basis of the X-ray crystal structures of closely related stable chiral carbene complexes $\left[\mathrm{Ru}\left(\mathrm{P}^{*}\right)\left(\mathrm{CPh}_{2}\right)\right](2)$ and $\left[\mathrm{Ru}\left(\mathrm{P}^{*}\right)(\mathrm{C}(\mathrm{Ph})\right.$ $\left.\left.\mathrm{CO}_{2} \mathrm{CH}_{2} \mathrm{CH}=\mathrm{CH}_{2}\right)\right](3)$ obtained from reactions of complex 1 with $\mathrm{N}_{2} \mathrm{CPh}_{2}$ and $\mathrm{N}_{2} \mathrm{C}(\mathrm{Ph}) \mathrm{CO}_{2} \mathrm{CH}_{2} \mathrm{CH}=\mathrm{CH}_{2}$, respectively.
\end{abstract}

\section{Introduction}

Despite a vast number of investigations on metal complexcatalyzed asymmetric intermolecular cyclopropanations of alkenes with diazo compounds ${ }^{1}$ and the discovery of several types of excellent catalysts for these transformations, such as semicorrin $^{-2}$ and bis(oxazoline $)^{3}$-copper and ruthenium-pybox complexes, ${ }^{4,5 a}$ the challenge remains to develop a robust, highly

\footnotetext{
City University of Hong Kong.

National Taiwan University.

$\S$ The Hong Kong Polytechnic University.

(1) Selected reviews: (a) Doyle, M. P.; Forbes, D. C. Chem. Rev. 1998 , 98, 911. (b) Doyle, M. P.; McKervey, M. A.; Ye, T. Modern Catalytic Methods for Organic Synthesis with Diazo Compounds; Wiley: New York, 1998. (c) Doyle, M. P.; Protopopova, M. N. Tetrahedron 1998, 54, 7919. (d) Doyle, M. P. In Comprehensive Organometallic Chemistry II, Vol. 12; Hegedus, L. S., Ed.; Pergamon: Oxford, 1995; p 387. (e) Togni, A.; Venanzi, L. M. Angew. Chem., Int. Ed. Engl. 1994, 33, 497.

(2) (a) Fritschi, H.; Leutenegger, U.; Pfaltz, A. Angew. Chem., Int. Ed. Engl. 1986, 25, 1005. (b) Fritschi, H.; Leutenegger, U.; Pfaltz, A. Helv. Chim. Acta 1988, 71, 1553.

(3) (a) Lowenthal, R. E.; Abiko, A.; Masamune, S. Tetrahedron Lett. 1990, 31, 6005. (b) Evans, D. A.; Woerpel, K. A.; Hinman, M. M.; Faul, M. M. J. Am. Chem. Soc. 1991, 113, 726. (c) Müller, D.; Umbricht, G.; Weber, B.; Pfaltz, A. Helv. Chim. Acta 1991, 74, 232.
}

selective catalyst for asymmetric intermolecular cyclopropanation of terminal alkenes with diazoacetates (reaction 1 in Scheme 1). Currently, in the case of the cyclopropanation of styrene with ethyl diazoacetate (EDA), a classical transformation for determining the catalyst effectiveness for reaction $1,{ }^{1}$ the semicorrin - and bis(oxazoline)-copper catalysts feature excellent enantioselectivity (ee up to $99 \%$ ) but with a rather low trans selectivity (trans/cis <4); the ruthenium-pybox catalysts result in high enantioselectivity and trans selectivity (ee up to $91 \%$, trans/cis up to 16) but suffer from low catalyst turnover $(\sim 100)$.

(4) (a) Nishiyama, H.; Itoh, Y.; Matsumoto, H.; Park, S.-B.; Itoh, K. J. Am. Chem. Soc. 1994, 116, 2223. (b) Nishiyama, H.; Itoh, Y.; Sugawara, Y.; Matsumoto, H.; Aoki, K.; Itoh, K. Bull. Chem. Soc. Jpn. 1995, 68 , 1247. (c) Park, S.-B.; Sakata, N.; Nishiyama, H. Chem. Eur. J. 1996, 2, 303. (d) Nishiyama, H.; Aoki, K.; Itoh, H.; Iwamura, T.; Sakata, N.; Kurihara, O.; Motoyama, Y. Chem. Lett. 1996, 1071.

(5) Abbreviations: (a) pybox $=2,6$-bis(oxazolinyl)pyridine. (b) $\mathrm{P}^{*}=$ 5,10,15,20-tetrakis $\{(1 S, 4 R, 5 R, 8 S)$-1,2,3,4,5,6,7,8-octahydro-1,4:5,8-dimethanoanthracene-9-yl\}porphyrinato dianion. (c) TPP = meso-tetraphenylporphyrinato dianion. (d) TMP $=$ meso-tetrakis(2,4,6-trimethylphenyl)porphyrinato dianion. (e) tmtaa $=7,16$-dihydro-6,8,15,17-tetramethyldibenzo$[b, i]-[1,4,8,11]$ tetraazacyclotetradecinato $(2-)$. (f) TTP $=$ meso-tetrakis $(p$ tolyl)porphyrinato dianion. 


\section{Scheme 1}
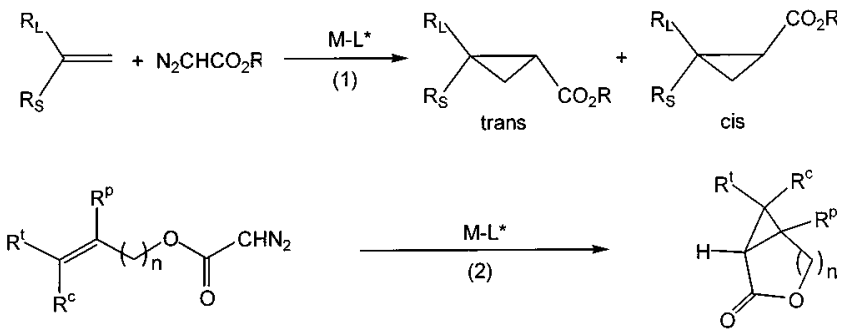

We were impressed by the extremely high catalyst turnovers of some metalloporphyrins in catalyzing alkene epoxidations (up to $10^{4}$ ). ${ }^{6}$ Exploring metalloporphyrin catalysts for asymmetric alkene cyclopropanation, the carbon analogue of epoxidation, would thus be of importance. In pioneering works by Kodadek and co-workers, ${ }^{7}$ chiral rhodium(III) porphyrins catalyze reaction 1 with thousands of turnovers and moderate enantiocontrol (ee up to 60\%). However, the trans/cis ratios obtained are low $(<1)$, which actually makes the rhodium porphyrins unique catalysts for cis selective cyclopropanations. Recently, Simonneaux and co-workers ${ }^{8}$ and our own group 9 independently discovered that chiral ruthenium porphyrins catalyze reaction 1 with high trans selectivity. In our case, the use of $\left[\mathrm{Ru}\left(\mathrm{P}^{*}\right)(\mathrm{CO})(\mathrm{EtOH})\right](\mathbf{1})$ bearing the celebrated Halterman's $D_{4}$-symmetric sterically encumbered porphyrin $\mathrm{P} * 5$ b, 10 gave rise to substantially higher enantio- and diastereocontrol (ee $91 \%$, trans/cis 24). Similar results were obtained subsequently by Berkessel and co-workers. ${ }^{11}$ In contrast to the detailed mechanistic studies for rhodium porphyrin-catalyzed cyclopropanations, ${ }^{12}$ the mechanism for the ruthenium porphyrincatalyzed analogues is rarely studied, ${ }^{13}$ and in no case has the observed enantioselectivity been rationalized.

In this paper, we report our extensive studies on the chiral ruthenium porphyrin-catalyzed reaction 1 and the first application of a ruthenium porphyrin catalyst to an asymmetric intramolecular cyclopropanation (reaction 2 in Scheme 1), with particular reference to the rationalization of the enantioselectivity in these catalytic systems. Under modified conditions, complex 1 catalyzes the EDA cyclopropanation of styrene with high trans selectivity (trans/cis $=36)$ and excellent enantioselectivity $(98 \%$ ee for the trans diastereomer). Extremely high catalyst turnovers $\left(>1 \times 10^{4}\right)$ could be obtained. The enantioselectivities observed in complex 1-catalyzed reactions 1 and 2 are rationalized on the basis of the crystal structures of closely related chiral carbene

(6) (a) Traylor, P. S.; Dolphin, D.; Traylor, T. G. J. Chem. Soc., Chem. Commun. 1984, 279. (b) Collman, J. P.; Wang, Z.; Straumanis, A.; Quelquejeu, M.; Rose, E. J. Am. Chem. Soc. 1999, 121, 460. (c) Yu, X.Q.; Huang, J.-S.; Yu, W.-Y.; Che, C.-M. J. Am. Chem. Soc. 2000, 122, 5337.

(7) (a) O’Malley, S.; Kodadek, T. Tetrahedron Lett. 1991, 32, 2445. (b) O’Malley, S.; Kodadek, T. Organometallics 1992, 11, 2299.

(8) (a) Galardon, E.; Le Maux, P.; Simonneaux, G. Chem. Commun. 1997, 927. (b) Galardon, E.; Roué, S.; Le Maux, P.; Simonneaux, G. Tetrahedron Lett. 1998, 39, 2333.

(9) Lo, W.-C.; Che, C.-M.; Cheng, K.-F.; Mak, T. C. W. Chem. Commun. 1997, 1205

(10) (a) Halterman, R. L.; Jan, S.-T. J. Org. Chem. 1991, 56, 5253. (b) Halterman, R. L.; Jan, S.-T.; Nimmons, H. L.; Standlee, D. J.; Khan, M. A. Tetrahedron 1997, 53, 11257.

(11) Frauenkron, M.; Berkessel, A. Tetrahedron Lett. 1997, 38, 7175

(12) (a) Maxwell, J. L.; Brown, K. C.; Bartley, D. W.; Kodadek, T. Science 1992, 256, 1544. (b) Brown, K. C.; Kodadek, T. J. Am. Chem. Soc. 1992, 114, 8336. (c) Bartley, D. W.; Kodadek, T. J. Am. Chem. Soc. 1993, 115, 1656.

(13) During the preparation of this manuscript, Simonneaux and coworkers reported some mechanistic studies on the intermolecular cyclopropanations of alkenes with EDA catalyzed by nonchiral ruthenium porphyrin [Ru(TPP)(CO)], see: Galardon, E.; Le Maux, P.; Simonneaux, G. Tetrahedron 2000, 56, 615 and ref 5c. complexes $\left[\mathrm{Ru}\left(\mathrm{P}^{*}\right)\left(\mathrm{CPh}_{2}\right)\right](\mathbf{2})$ and $\left[\mathrm{Ru}(\mathrm{P} *)\left(\mathrm{C}(\mathrm{Ph}) \mathrm{CO}_{2} \mathrm{CH}_{2} \mathrm{CH}=\right.\right.$ $\mathrm{CH}_{2}$ )] (3). To our knowledge, complexes $\mathbf{2}$ and $\mathbf{3}$ contribute the first isolated chiral metalloporphyrin carbene complexes and the latter represents a unique metalloporphyrin carbene complex whose carbene group bears a pendant alkene $\mathrm{C}=\mathrm{C}$ bond.

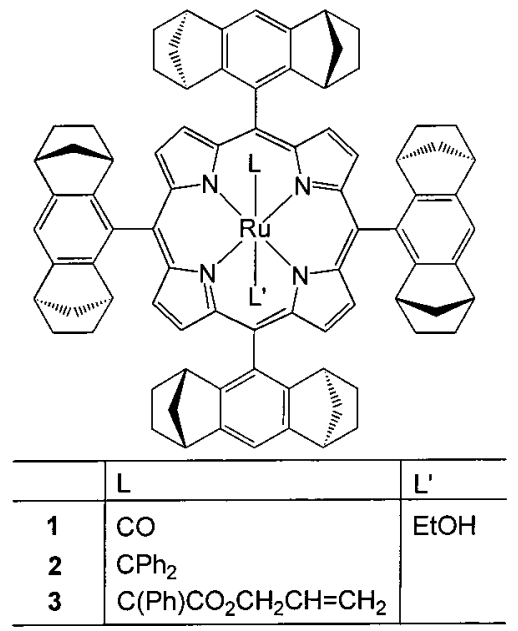

\section{Results}

Asymmetric Intermolecular Cyclopropanation Catalyzed by $\left[\operatorname{Ru}\left(\mathbf{P}^{*}\right)(\mathrm{CO})(\mathrm{EtOH})\right](1)$. (i) Effects of Temperature and Catalyst Loading. We inspected the reactions of a series of terminal alkenes (4), mainly the monosubstituted, with various diazoacetates (5) in the presence of catalytic amounts of complex 1. ${ }^{14}$ The results obtained in dichloromethane for the EDA (5a) cyclopropanation of styrene (4a), 1,1-diphenylethene (4b), $\alpha$-methylstyrene (4c), and para-substituted styrenes $p-\mathrm{X}-\mathrm{C}_{6} \mathrm{H}_{4}$ $\mathrm{CH}=\mathrm{CH}_{2}(\mathrm{X}=\mathrm{Cl}, \mathbf{4 d} ; \mathrm{F}, \mathbf{4 e} ; \mathrm{Me}, \mathbf{4 f} ; \mathrm{MeO}, \mathbf{4 g})$ are summarized in Table 1 (loading of $\mathbf{1}=0.005 \mathrm{~mol} \%$ for entry 4 and 0.05 mol $\%$ for the others). Note that all the reactions in Table 1 were performed at room temperature except for entries $2\left(0{ }^{\circ} \mathrm{C}\right)$ and $3\left(-40{ }^{\circ} \mathrm{C}\right)$. As already described in the previous communication, ${ }^{9}$ reaction 1 catalyzed by complex $\mathbf{1}(0.05 \mathrm{~mol} \%)$ at room temperature for alkenes $\mathbf{4 a}-\mathbf{d}, \mathbf{f}, \mathbf{g}$ features high trans selectivity and enantioselectivity. The catalyst turnovers are generally $>1000$. Similar results were obtained for $\mathbf{4 e}$ (entry 8).

Examination of entries 1-3 discloses the temperature dependence of the trans selectivity and enantioselectivity. Higher enantiocontrol for the trans isomer $\mathbf{6 a}$ was achieved at lower reaction temperature; the cyclopropanation at $-40{ }^{\circ} \mathrm{C}$ afforded 6a in an ee as high as $98 \%$ (entry 3 ). The temperature dependence of trans selectivity is impressive. By lowering the reaction temperature from $\sim 20$ to $-40{ }^{\circ} \mathrm{C}$, the trans/cis ratio increased from 18 (entry 1 ) to 36 (entry 3 ). This contrasts with the diazomethane cyclopropanation of alkenes catalyzed by $\left[\mathrm{Pd}(\mathrm{OAc})_{2}\right]_{3}$, whose trans/cis ratio decreases with decreasing temperature. ${ }^{15}$ On the other hand, decreasing the loading of complex 1 led to an increase of catalyst turnovers. When 0.005 mol \% of 1 was employed, turnovers of $1.1 \times 10^{4}$ were obtained (entry 4).

(ii) Effect of Diazoacetate. Table 2 shows the results for the cyclopropanation of styrene with a variety of other diazo-

(14) Nonterminal alkenes cis/trans- $\beta$-methylstyrene and trans-stilbene were found to be almost unreactive toward the intermolecular cyclopropanation with diazoacetates such as EDA in the presence of catalyst $\mathbf{1}$ under the same conditions as those employed for terminal alkenes $\mathbf{4}$, with only trace amounts of the corresponding cyclopropanes formed (but $>95 \%$ yields of dimerization products of EDA were detected).

(15) Vallgarda, J.; Hacksell, U. Tetrahedron Lett. 1991, 32, 5625. 
Table 1. Asymmetric Cyclopropanation of Styrene and Its Derivatives with Ethyl Diazoacetate (5a) Catalyzed by $\left[\mathrm{Ru}\left(\mathrm{P}^{*}\right)(\mathrm{CO})(\mathrm{EtOH})\right](\mathbf{1})^{a}$

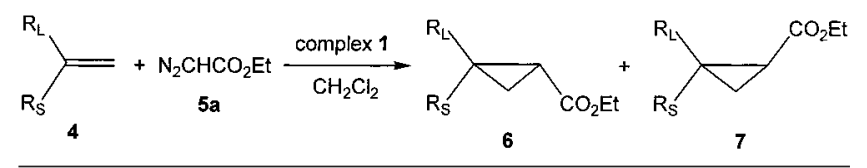

\begin{tabular}{|c|c|c|c|c|c|c|c|c|}
\hline \multirow[b]{2}{*}{ entry } & \multicolumn{3}{|c|}{$\begin{array}{c}\text { substrate (4) } \\
\left(\mathrm{R}_{\mathrm{L}}=p-\mathrm{X}-\mathrm{C}_{6} \mathrm{H}_{4}\right)\end{array}$} & \multirow{2}{*}{$\begin{array}{l}\text { yield } \\
(\%)^{b} \\
(6+7)\end{array}$} & \multirow{2}{*}{$\begin{array}{c}\text { trans/cis } \\
\text { ratio }^{c} \\
(\mathbf{6} / 7)\end{array}$} & \multicolumn{2}{|c|}{$\% \mathrm{ee}^{d}$} & \multirow{2}{*}{$\begin{array}{l}\text { turnovers } \\
\text { (1) }\end{array}$} \\
\hline & & $\mathrm{R}_{\mathrm{S}}$ & $\mathrm{X}$ & & & $\overline{6^{e}}$ & 7 & \\
\hline 1 & $4 a$ & $\mathrm{H}$ & $\mathrm{H}$ & 83 & 18 & 87 & 4 & $1.7 \times 10^{3}$ \\
\hline $2^{f}$ & $4 a$ & $\mathrm{H}$ & $\mathrm{H}$ & 63 & 24 & 91 & 4 & $1.3 \times 10^{3}$ \\
\hline $3^{g}$ & $4 a$ & $\mathrm{H}$ & $\mathrm{H}$ & 52 & 36 & 98 & nd & $1.0 \times 10^{3}$ \\
\hline $4^{h}$ & $4 a$ & $\mathrm{H}$ & $\mathrm{H}$ & 57 & 9.0 & 83 & 2 & $1.1 \times 10^{4}$ \\
\hline 5 & $4 b$ & $\mathrm{Ph}$ & $\mathrm{H}$ & 76 & & $81^{i}$ & & $1.5 \times 10^{3}$ \\
\hline 6 & $4 c$ & $\mathrm{Me}$ & $\mathrm{H}$ & 69 & 3.0 & 87 & 35 & $1.4 \times 10^{3}$ \\
\hline 7 & 4d & $\mathrm{H}$ & $\mathrm{Cl}$ & 66 & 23 & 90 & 4 & $1.3 \times 10^{3}$ \\
\hline 8 & $4 e$ & $\mathrm{H}$ & $\mathrm{F}$ & 83 & 19 & 87 & 3 & $1.7 \times 10^{3}$ \\
\hline 9 & $4 f$ & $\mathrm{H}$ & $\mathrm{Me}$ & 78 & 18 & 81 & 9 & $1.6 \times 10^{3}$ \\
\hline 10 & $4 g$ & $\mathrm{H}$ & $\mathrm{MeO}$ & 61 & 15 & 85 & 8 & $1.2 \times 10^{3}$ \\
\hline
\end{tabular}

${ }^{a}$ Reactions were performed in $\mathrm{CH}_{2} \mathrm{Cl}_{2}$ at room temperature for 20 $\mathrm{h}$ with a 1:5a:4 molar ratio of 1:2000:10000. ${ }^{b}$ Isolated yields based on 5a. ${ }^{c}$ Determined by GC-MS. ${ }^{d}$ Determined by chiral HPLC (chiral column: Daicel OJ) for $\mathbf{6 a}, \mathbf{b}, \mathbf{g}$ and $\mathbf{7 a}, \mathbf{b}, \mathbf{g}$, by chiral GC (chiral column: J \& W Scientific Cyclodex B, $30 \mathrm{~m}$ ) for $\mathbf{6 c}, \mathbf{e}$ and $\mathbf{7 c}, \mathbf{e}$, and by analyzing the $l$-menthyl ester by Pfaltz's method (ref $2 b$ ) for the others. ${ }^{e}$ Configuration: $(1 S, 2 S) .{ }^{f}$ At $0{ }^{\circ} \mathrm{C} .{ }^{g}$ At $-40{ }^{\circ} \mathrm{C} .{ }^{h} \mathbf{1}: 5 a: 4$ molar ratio of 1:20000:100000 ${ }^{i}(S)$-Configuration.

Table 2. Asymmetric Cyclopropanation of Styrene with Various Diazoacetates (5) Catalyzed by $\left[\mathrm{Ru}\left(\mathrm{P}^{*}\right)(\mathrm{CO})(\mathrm{EtOH})\right](\mathbf{1})$

\begin{tabular}{|c|c|c|c|c|c|c|}
\hline \multirow[b]{2}{*}{ entry } & \multicolumn{2}{|c|}{$\mathrm{N}_{2} \mathrm{CHCO}_{2} \mathrm{R}(\mathbf{5})$} & \multirow{2}{*}{$\begin{array}{c}\text { yield }(\%) \\
\left(6^{\prime}+7^{\prime}\right)\end{array}$} & \multirow{2}{*}{$\begin{array}{l}\text { trans/cis ratio } \\
\left(6^{\prime}+7^{\prime}\right)\end{array}$} & \multicolumn{2}{|c|}{$\%$ ee } \\
\hline & & $\mathrm{R}$ & & & $\overline{6^{\prime}}$ & $\overline{7^{\prime}}$ \\
\hline 1 & $5 b$ & $\mathrm{Me}$ & 68 & 12 & 86 & 3 \\
\hline 2 & $5 \mathbf{a}$ & Et & 83 & 18 & 87 & 4 \\
\hline 3 & $5 c$ & $\mathrm{Bu}^{\mathrm{t}}$ & 62 & 26 & 82 & 11 \\
\hline 4 & $5 d$ & $l$-menthyl & 77 & 11 & $67^{a}$ & $95^{a}$ \\
\hline 5 & $5 e$ & $d$-menthyl & 72 & 19 & $64^{a}$ & $90^{a}$ \\
\hline
\end{tabular}

a \% de (diastereomeric excess).

acetates $\mathrm{N}_{2} \mathrm{CHCO}_{2} \mathrm{R}\left(\mathrm{R}=\mathrm{Me}, \mathbf{5} \mathbf{b} ; \mathrm{Bu}^{\mathrm{t}}, \mathbf{5} \mathbf{c} ;\right.$ l-menthyl, 5d; $d$-menthyl, 5e) as compared with those obtained by using $\mathbf{5 a}$. In the cases of $\mathbf{5 a}-\mathbf{c}$ (entries 1-3), increasing the steric hindrance of $\mathrm{R}$ results in an increase of trans selectivity, with the trans/cis ratio following the order $\mathrm{Me}<\mathrm{Et}<\mathrm{Bu}^{\mathrm{t}}$. This is consistent with the results observed for other cyclopropanation systems. ${ }^{2-4}$ However, the results obtained for $\mathbf{5 d}$ and $\mathbf{5 e}$ are surprising (entries 4 and 5). First, contrary to the other systems, $, 2,3 \mathrm{a}, 4$ in which the cyclopropanations with $\mathbf{5 d}$ generally give higher trans selectivity than those with $\mathbf{5 a}$, the selectivity obtained for $\mathbf{5} \mathbf{d}$ in this work is lower. Second, while the ee's of the trans cyclopropanes $\mathbf{6}^{\prime}$ are much higher than those of their cis counterparts $\mathbf{7}^{\prime}$ for $\mathbf{5 a}-\mathbf{c}$, the de's of $\mathbf{6}^{\prime}$ are substantially lower than those of $\mathbf{7}^{\prime}$ in the cases of $\mathbf{5} \mathbf{d}$ and $\mathbf{5 e}$.

(iii) Effect of Solvent. Running the cyclopropanation of styrene with EDA in various solvents, including toluene, dichloromethane, benzene, $n$-hexane, tetrahydrofuran, and diethyl ether, disclosed a dependence of the trans selectivity on the nature of the solvent, with trans/cis ratios rather similar for the former four solvents $(15-19)$ but considerably higher for the ethers (23 and 29) (see Table S1 in Supporting Information). For iron porphyrin-catalyzed cyclopropanation of styrene with EDA, ${ }^{16}$ donor solvents were found to enhance the trans selectivity. In this work, the trans selectivity is higher in diethyl ether (trans/cis 29) than in tetrahydrofuran (trans/cis 23), a result different from that of the iron porphyrin catalyst. ${ }^{16}$

Despite the solvent dependence of trans selectivity, the effect of solvent on the enantioselectivity for the predominant, trans isomer $\mathbf{6} \mathbf{a}$ is rather small, with the observed ee's in a narrow range of $87-91 \%$ for the six solvents examined. What is different is the ee's attained for the cis isomer $\mathbf{7 a}$, which are substantially higher in diethyl ether $(18 \%)$ and tetrahydrofuran $(14 \%)$ than in other solvents $(0-6 \%)$. As to the total yield of 6a and $7 \mathbf{a}$, the highest (83\%) was obtained in dichloromethane. In diethyl ether, such a yield is lower (74\%).

(iv) Effect of Para Substituent of Styrenes. The cyclopropanation rates of para-substituted styrenes $p-\mathrm{X}-\mathrm{C}_{6} \mathrm{H}_{4} \mathrm{CH}=\mathrm{CH}_{2}$ $\left(\mathrm{X}=\mathrm{MeO}, \mathbf{4 g} ; \mathrm{Me}, \mathbf{4 f} ; \mathrm{Cl}, \mathbf{4 d} ; \mathrm{CF}_{3}, \mathbf{4 h}\right)$ relative to that of styrene (4a) were estimated through competition experiments for the EDA cyclopropanation in dichloromethane by employing equimolar amounts of styrene and the para-substituted derivatives. The relative rates $k_{\mathrm{X}} / k_{\mathrm{H}}$, defined as the molar ratio of resultant cyclopropanes $(\mathbf{6}+\mathbf{7}) /(\mathbf{6 a}+\mathbf{7 a})$, were found to be 3.20 (4g), 1.65 (4f), 1.44 (4d), and 0.84 (4h). Basically, electrondonating para substituents accelerate, whereas electron-withdrawing para substituents retard, the cyclopropanation reactions.

Attempts were made to correlate the above relative rates with Hammett constants of the para substituents. Unlike the systems catalyzed by nonchiral $[\mathrm{Ru}(\mathrm{TPP})(\mathrm{CO})]^{5 \mathrm{c}, 13}$ or iron porphyrins, ${ }^{16}$ whose $\log \left(k_{\mathrm{X}} / k_{\mathrm{H}}\right)$ vs $\sigma$ plots both give a good linearity, such a plot for complex 1-catalyzed systems shows scattered data points. Interestingly, plotting $\log \left(k_{\mathrm{X}} / k_{\mathrm{H}}\right)$ against $\sigma^{+}$resulted in a good linearity (see Figure S1 in Supporting Information), with a $\rho^{+}$value of $-0.44 \pm 0.09$.

(v) Effect of Conjugation. Competition experiments of 1,1diphenylethene (4b), trans-2-methyl-1,3-pentadiene (4i), and 1-hexene $(\mathbf{4 j})$ vs styrene reveal a cyclopropanation rate order $\mathbf{4 b}>\mathbf{4 i}>\mathbf{4 j}\left(k_{\mathrm{X}} / k_{\mathrm{H}}=7.3\right.$ (4b), 3.3 (4i), 0.03 (4j)). ${ }^{17}$ This order is parallel to that of the extent of conjugation $\mathbf{4 b}>\mathbf{4 i}>$ $\mathbf{4 j}$. A comparison of the $k_{\mathrm{X}} / k_{\mathrm{H}}$ values among alkenes $\mathbf{4 b}, \mathbf{d}, \mathbf{f}-\mathbf{j}$ indicates that the alkene $\mathbf{4 b}$ is cyclopropanated most rapidly, in agreement with a larger extent of conjugation in the transition state expected for this alkene than for any of $\mathbf{4 d , f}-\mathbf{j}$.

Asymmetric Intramolecular Cyclopropanation Catalyzed by $\left[\mathbf{R u}\left(\mathbf{P}^{*}\right)(\mathbf{C O})(\mathbf{E t O H})\right](\mathbf{1})$. The catalytic behavior of complex 1 toward reaction 2 for a series of allylic or homoallylic diazoacetates was examined. The results obtained for several allylic diazoacetates that lack substitution on the proximal position of the $\mathrm{C}=\mathrm{C}$ double bond (i.e., $\mathrm{R}^{\mathrm{p}}=\mathrm{H}$ in Scheme 1) are shown in Table 3. With diazoacetates $\mathrm{N}_{2} \mathrm{CHCO}_{2} \mathrm{CH}_{2} \mathrm{CH}=$ $\mathrm{CR}^{\mathrm{c}} \mathrm{R}^{\mathrm{t}}(\mathbf{8} \mathbf{a}-\mathbf{e})$ as substrates, the corresponding cyclopropyl lactones $9 \mathbf{a}-\mathbf{e}$ were obtained in moderate yields with up to $85 \%$ ee.

A comparison of the results in Table 3 with those reported for the dirhodium(II) carboxamidate catalyst ${ }^{18}$ reveals several unusual features of catalyst $\mathbf{1}$. First, in the case of the dirhodium catalyst, $\mathbf{8 a}, \mathbf{b}$ are excellent substrates and afford considerably higher ee's than trans-cinnamyl diazoacetate $(\mathbf{8 d})$; however, $8 \mathbf{d}$ has proven to be the best substrate for catalyst $\mathbf{1}$, affording a much higher ee than $\mathbf{8 a}, \mathbf{b}$. Second, while the dirhodium catalyst

(16) Wolf, J. R.; Hamaker, C. G.; Djukic, J.-P.; Kodadek, T.; Woo, L. K. J. Am. Chem. Soc. 1995, 117, 9194.

(17) The trans/cis ratio was found to be $\sim 1$ and 1.3 for $\mathbf{4 i}$ and $\mathbf{4 j}$, respectively. In the case of $\mathbf{4 i}$, only the terminal $\mathrm{C}=\mathrm{C}$ bond was cyclopropanated.

(18) Doyle, M. P.; Austin, R. E.; Bailey, A. S.; Dwyer, M. P.; Dyatkin, A. B.; Kalinin, A. V.; Kwan, M. M. Y.; Liras, S.; Oalmann, C. J.; Pieters, R. J.; Protopopova, M. N.; Raab, C. E.; Roos, G. H. P.; Zhou, Q.-L.; Martin, S. F. J. Am. Chem. Soc. 1995, 117, 5763. 
Table 3. Asymmetric Intramolecular Cyclopropanation of Allylic Diazoacetates $(\mathbf{8})$ Catalyzed by $\left[\mathrm{Ru}\left(\mathrm{P}^{*}\right)(\mathrm{CO})(\mathrm{EtOH})\right](\mathbf{1})^{a}$
8<smiles>[R]/C([3H])=C/COC(=O)C#N</smiles>

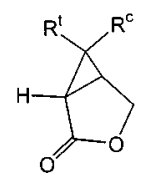

9

\begin{tabular}{cccccc}
\hline & \multicolumn{3}{c}{ substrate $(\mathbf{8})$} & & \\
\cline { 2 - 4 } entry & & $\mathrm{R}^{c}$ & $\mathrm{R}^{\mathrm{t}}$ & isolated yield of $\mathbf{9}(\%)^{b}$ & $\%$ ee of $\mathbf{9}^{c}$ \\
\hline 1 & $\mathbf{8 a}$ & $\mathrm{H}$ & $\mathrm{H}$ & 45 & $24(1 R, 5 S)$ \\
2 & $\mathbf{8 b}$ & $\mathrm{Me}$ & $\mathrm{Me}$ & 65 & $36(1 S, 5 R)$ \\
3 & $\mathbf{8 c}$ & $\mathrm{H}$ & $\mathrm{Me}$ & 65 & $28(\mathrm{nd})$ \\
4 & $\mathbf{8 d}$ & $\mathrm{H}$ & $\mathrm{Ph}$ & 60 & $85(1 S, 5 R)$ \\
5 & $\mathbf{8 e}$ & $\mathrm{Ph}$ & $\mathrm{H}$ & 24 (anti) $^{d}$ & $53(1 S, 5 R)$ \\
\hline
\end{tabular}

${ }^{a}$ Reactions were performed in $\mathrm{CH}_{2} \mathrm{Cl}_{2}$ at room temperature for 18 $\mathrm{h}$ with a 1:8 molar ratio of $1: 150 .{ }^{b}$ On the basis of consumed substrates. ${ }^{c}$ Absolute configurations were assigned by comparing the elution orders of the enantiomers as reported in ref 18 . The ee's were determined by chiral GC (column: Chiraldex G-TA, $30 \mathrm{~m}$ ). ${ }^{d}$ The syn isomer was formed in $18 \%$ yield and $24 \%$ ee.

generates the predominant enantiomer of the lactone $9 \mathbf{d}$ in $(1 R, 5 S)$ configuration, catalyst $\mathbf{1}$ produces $\mathbf{9 d}$ predominantly in $(1 S, 5 R)$ configuration. Finally, in the case of substrate $8 \mathbf{e}$, catalyst 1 gives rise to a mixture of lactones anti- and syn-9e with the major product being the anti- rather than the expected syn-isomer (see entry 5), ${ }^{19}$ different from the dirhodium catalyst, which has not been reported to afford anti-9e.

Note that complex $\mathbf{1}$ was found to be ineffective in catalyzing reaction 2 for the allylic diazoacetates with $\mathrm{R}^{\mathrm{p}}=$ methyl or phenyl. Homoallylic diazoacetates such as 3-butenyl diazoacetate (10) appeared to be inferior to $\mathbf{8 a}-\mathbf{e}$. Under the same conditions as indicated in Table 3, reaction 2 for $\mathbf{1 0}$ gave the cyclopropyl lactone in only $10 \%$ yield with a rather low enantiocontrol (29\% ee).

Reactivity of $\left[\mathrm{Ru}\left(\mathrm{P}^{*}\right)(\mathrm{CO})(\mathrm{EtOH})\right]$ (1) toward Diazoacetates: Isolation of Chiral Carbene Complexes $\left[\mathbf{R u}\left(\mathbf{P}^{*}\right)\right.$ $\left.\left(\mathrm{CPh}_{2}\right)\right](2)$ and $\left[\mathrm{Ru}(\mathrm{P} *)\left(\mathrm{C}(\mathrm{Ph}) \mathrm{CO}_{2} \mathrm{CH}_{2} \mathrm{CH}=\mathrm{CH}_{2}\right)\right]$ (3). Treatment of complex 1 with excess diphenyldiazomethane $\left(\mathrm{N}_{2} \mathrm{CPh}_{2}\right.$, 11) in benzene at room temperature readily gave rise to analytically pure chiral ruthenium diphenylcarbene complex 2 as a dark red crystalline solid in $86 \%$ isolated yield (reaction 3 in Scheme 2). The reaction between 1 and an $\alpha$-substituted allylic diazoacetate, $\mathrm{N}_{2} \mathrm{C}(\mathrm{Ph}) \mathrm{CO}_{2} \mathrm{CH}_{2} \mathrm{CH}=\mathrm{CH}_{2}$ (12), in dichloromethane at room temperature afforded analytically pure chiral ruthenium phenyl(allyloxycarbonyl)carbene complex $\mathbf{3}$ in a similar isolated yield (reaction 4 in Scheme 2). Both the monocarbene species $\mathbf{2}$ and $\mathbf{3}$ are rather stable, neither of which was found to undergo stoichiometric inter- or intramolecular cyclopropanation with an alkene. For instance, treating $\mathbf{2}$ with styrene in benzene caused no detectable reaction even at the boiling temperature of the solvent; refluxing a solution of $\mathbf{3}$ in toluene overnight under nitrogen resulted in no appreciable reaction (as revealed by UV-vis measurements and GC-MS).

Reactions 3 and 4 clearly provide precedents for the formation of ruthenium carbene complexes bearing a sterically demanding porphyrin macrocycle (such as $\mathrm{P}^{*}$ ) from reaction of a carbonyl ruthenium porphyrin with a diazo compound. ${ }^{20}$ Previously, Collman and co-workers ${ }^{21}$ pioneered the isolation of ruthenium porphyrins with alkyl- and (alkoxycarbonyl)carbene axial

(19) Currently, the cause of this phenomenon is not yet clear. Presumably, the complex 1-catalyzed cyclopropanation of $\mathbf{8 e}$ proceeds via a stepwise mechanism whose transition state features a broken $\mathrm{PhCH}=\mathrm{CH} \pi$-bond so that the $\mathrm{PhCH}$ moiety can rotate about the remaining $\mathrm{C}-\mathrm{C} \sigma$-bond before the lactone $\mathbf{9 e}$ is formed.
Scheme 2
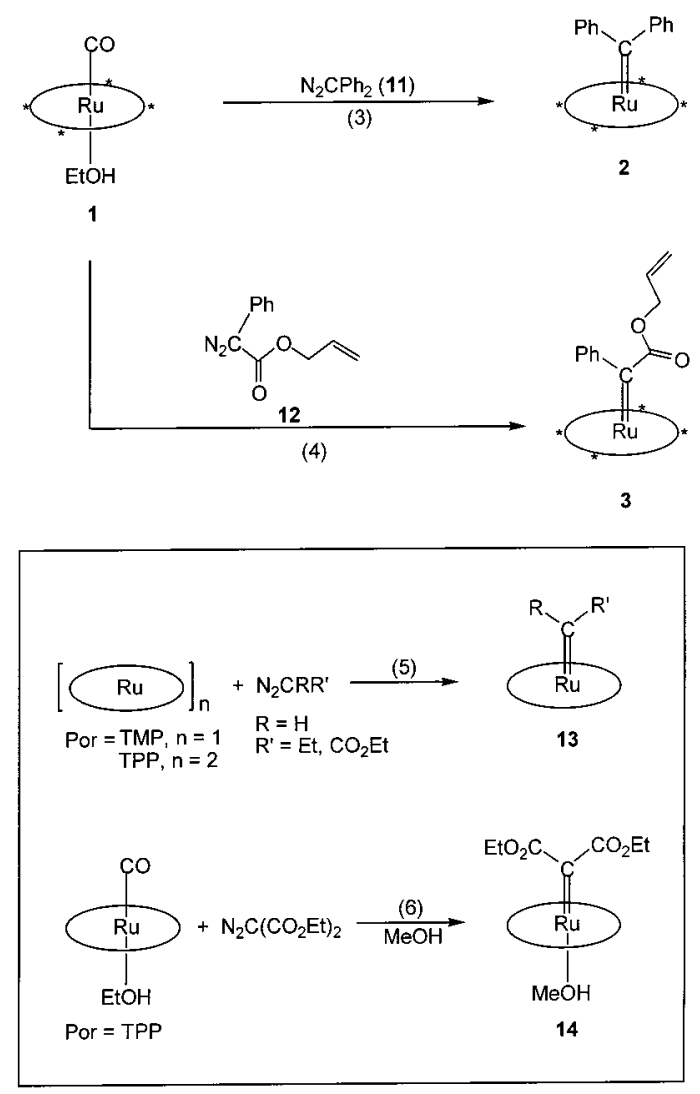

ligands, $\left[\mathrm{Ru}(\mathrm{Por})\left(\mathrm{CRR}^{\prime}\right)\right]\left(\mathbf{1 3}\right.$, Por $=\mathrm{TPP}$ or $\left.\mathrm{TMP}^{5 \mathrm{~d}}\right)$, from $[\mathrm{Ru}-$ $(\mathrm{TPP})]_{2}$ or $[\mathrm{Ru}(\mathrm{TMP})]$ precursors (reaction 5 in Scheme 2). The synthesis of a ruthenium di(ethoxycarbonyl)carbene complex bearing a sterically unencumbered porphyrin ligand, $[\mathrm{Ru}(\mathrm{TPP})$ $\left.\left(\mathrm{C}\left(\mathrm{CO}_{2} \mathrm{Et}\right)_{2}\right)(\mathrm{MeOH})\right](\mathbf{1 4})$, from the corresponding carbonyl precursor and diazo compound was recently reported by Simonneaux and co-workers (reaction 6 in Scheme 2), ${ }^{22}$ which represents the first structurally characterized ruthenium porphyrin carbene complex.

Spectral Features of $\left[\mathrm{Ru}\left(\mathrm{P}^{*}\right)\left(\mathrm{CPh}_{2}\right)\right](2)$ and $\left[\mathrm{Ru}\left(\mathrm{P}^{*}\right)\right.$ $\left.\left(\mathrm{C}(\mathrm{Ph}) \mathrm{CO}_{2} \mathrm{CH}_{2} \mathrm{CH}=\mathrm{CH}_{2}\right)\right]$ (3). Both complexes $\mathbf{2}$ and $\mathbf{3}$ exhibit a low-field ${ }^{13} \mathrm{C}$ NMR signal that can be attributed to the resonance of the coordinated carbene $\mathrm{C}$ atom $(\delta=315(2)$, 285 (3)). Such resonances for other related ruthenium carbene complexes are located in the range $\delta 271-306 .{ }^{4 c, 22,23}$ In the FAB mass spectra of $\mathbf{2}$ and $\mathbf{3}$, the cluster peaks attributable to the corresponding parent ions appear at $\mathrm{m} / \mathrm{z}=1409$ (2) and 1417 (3).

The ${ }^{1} \mathrm{H}$ NMR spectra of $\mathbf{2}$ and $\mathbf{3}$ (Figures S2 and S3 in Supporting Information) correspond to diamagnetic species, like those of alkyl- or (alkoxycarbonyl)carbene complexes $13^{21}$ and 14. ${ }^{22}$ In contrast to the signals of the porphyrin pyrrole protons for 13 and 14, which invariably appear as a singlet, such signals for $\mathbf{2}$ and $\mathbf{3}$ appear as a multiplet centered at $\delta 8.26$ (2) and

(20) Although our preliminary observations on the reaction between complex 1 and EDA in benzene through ${ }^{1} \mathrm{H}$ NMR and UV-vis measurements suggest the formation of a ruthenium porphyrin carbene complex, $\left[\mathrm{Ru}\left(\mathrm{P}^{*}\right)\left(\mathrm{CHCO}_{2} \mathrm{Et}\right)\right]$, such a complex was not isolated or fully characterized (see ref 9 ).

(21) (a) Collman, J. P.; Brothers, P. J.; McElwee-White, L.; Rose, E.; Wright, L. J. J. Am. Chem. Soc. 1985, 107, 4570. (b) Collman, J. P.; Rose, E.; Venburg, G. D. J. Chem. Soc., Chem. Commun. 1993, 934.

(22) Galardon, E.; Le Maux, P.; Toupet, L.; Simonneaux, G. Organometallics 1998, 17, 565 .

(23) Klose, A.; Solari, E.; Floriani, C.; Geremia, S.; Randaccio, L. Angew. Chem., Int. Ed. 1998, 37, 148. 
Table 4. Crystal Data and Structure Refinement for $\left[\mathrm{Ru}\left(\mathrm{P}^{*}\right)\left(\mathrm{CPh}_{2}\right)\right](\mathbf{2}) \cdot 2 \mathrm{CH}_{2} \mathrm{Cl}_{2}$ and $\left[\mathrm{Ru}\left(\mathrm{P}^{*}\right)\left(\mathrm{C}(\mathrm{Ph}) \mathrm{CO}_{2} \mathrm{CH}_{2} \mathrm{CH}=\mathrm{CH}_{2}\right)\right](3) \cdot 3 \mathrm{CH}_{2} \mathrm{Cl}_{2}$

\begin{tabular}{lll}
\hline & \multicolumn{1}{c}{ complex $\mathbf{c}$} & \\
\hline empirical formula & $\mathrm{C}_{97} \mathrm{H}_{86} \mathrm{~N}_{4} \mathrm{Ru} \cdot 2 \mathrm{CH}_{2} \mathrm{Cl}_{2}$ & $\mathrm{C}_{95} \mathrm{H}_{86} \mathrm{~N}_{4} \mathrm{O}_{2} \mathrm{Ru}_{3} \cdot 3 \mathrm{CH}_{2} \mathrm{Cl}_{2}$ \\
formula weight & 1578.62 & 1671.53 \\
$T, \mathrm{~K}$ & $295(2)$ & $294(2)$ \\
$\lambda, \AA$ & 0.71073 & 0.71073 \\
cryst syst & orthorhombic & monoclinic \\
space group & $P 2{ }_{1} 2_{1} 2_{1}$ & $P 2_{1}$ \\
$a, \AA$ & $14.6870(3)$ & $14.265(1)$ \\
$b, \AA$ & $20.6491(3)$ & $18.125(1)$ \\
$c, \AA$ & $27.5075(2)$ & $16.705(1)$ \\
$\beta$, deg & & $98.612(2)$ \\
$V, \AA$ & $4270.4(6)$ \\
$Z$ & $8342.3(2)$ & 2 \\
$F(000)$ & 4 & 1740 \\
density (calcd), Mg/m ${ }^{3}$ & 3296 & 1.300 \\
abs coeff, mm & 1.257 & 0.42 \\
index ranges & 0.366 & $-17 \leq h \leq 18,-19 \leq k \leq 23,-21 \leq l \leq 21$ \\
no. of reflns collected & $-18 \leq h \leq 19,-26 \leq k \leq 22,-35 \leq l \leq 35$ & 28653 \\
no. of independent reflns & 49593 & 15800 \\
abs correction & 19115 & $\mathrm{SADABS}$ \\
max/min transmission & $\mathrm{SADABS}$ & $0.9512 / 0.9313$ \\
refinement method & $0.8313 / 0.6336$ & full-matrix least-squares on $F^{2}$ \\
data/restraints/parameters & full-matrix least-squares on $F^{2}$ & $15800 / 14 / 949$ \\
final $R$ indices $(I>2 \sigma(I))$ & $19115 / 0 / 964$ & $\mathrm{R} 1=0.061$ \\
goodness-of-fit on $F^{2}$ & $\mathrm{R} 1=0.081$ & 0.960 \\
absolute structure parameter & 1.017 & $-0.01(3)$ \\
largest diff peak/hole, e $\AA^{-3}$ & $0.00(4)$ & $0.918 /-0.769$ \\
\hline
\end{tabular}

8.35 (3) with a pattern resembling that of an $\mathrm{AB}$ system. The bridgehead protons of the norbornane moieties in the $\mathrm{P}^{*}$ ligand of either $\mathbf{2}$ or $\mathbf{3}$ give a total of eight signals (appearing as four doublets) in equal intensity, different from the two singlets observed for the corresponding protons in the dioxoruthenium(VI) complex bearing the same porphyrin macrocycle. ${ }^{24}$ The signal patterns of the carbene phenyl groups in $\mathbf{2}$ and $\mathbf{3}$ are normal. However, the $\mathrm{OCH}_{2}$ protons of the allyloxycarbonyl group in $\mathbf{3}$ give two well-separated sets of double doublets, dramatically different from the single doublet observed for these protons in allyl diazoacetate $\mathbf{1 2} .^{25}$

The UV-vis spectrum of $\mathbf{2}$ features two Soret bands located at 397 and $432 \mathrm{~nm}$, respectively. This resembles the alkylcarbene complex $\left[\mathrm{Ru}(\mathrm{TTP})\left(\mathrm{CHCH}_{3}\right)\right](\mathbf{1 3 a})$ reported by Collman and co-workers, ${ }^{21 a}$ whose UV-vis spectrum also shows two Soret bands (395 and $421 \mathrm{~nm}$ ). Metalloporphyrins having this property are uncommon. In addition to complexes 2 and 13a, a few nitrido- or nitrosylosmium porphyrins reported by Buchler, Gouterman, and co-workers ${ }^{26}$ serve as additional examples. On the other hand, compared with the alkylcarbene complex 13a, the arylcarbene complex $\mathbf{2}$ shows an appreciably red-shifted $\beta$ band (13a, $527 \mathrm{~nm} ; 2,536 \mathrm{~nm})$. It is worth noting that while the $\beta$ band of $\mathbf{2}$ is more similar to that of the di(alkoxycarbonyl)carbene complex $14(531 \mathrm{~nm}),{ }^{22}$ there is only one Soret band in the UV-vis spectrum of 14. The UV-vis spectrum of $\mathbf{3}$, which bears the $\mathrm{C}(\mathrm{Ph}) \mathrm{CO}_{2} \mathrm{R}$ group, shows a single Soret band (402 nm) with an obvious shoulder ( 442 nm) on its red side, in contrast to the double Soret bands observed for the $\mathrm{CPh}_{2}$ complex 2 and a single Soret band for the $\mathrm{C}\left(\mathrm{CO}_{2} \mathrm{R}\right)_{2}$ complex 14.

X-ray Crystal Structure Determinations of $\left[\mathbf{R u}\left(\mathbf{P}^{*}\right)\left(\mathbf{C P h}_{2}\right)\right]$ (2) and $\left[\mathrm{Ru}\left(\mathrm{P}^{*}\right)\left(\mathrm{C}(\mathrm{Ph}) \mathrm{CO}_{2} \mathrm{CH}_{2} \mathrm{CH}=\mathrm{CH}_{2}\right)\right](3)$. Complexes 2

(24) Lai, T.-S.; Zhang, R.; Cheung, K.-K.; Kwong, H.-L.; Che, C.-M. Chem. Commun. 1998, 1583.

(25) This striking feature probably arises from a significant steric interaction in $\mathbf{3}$ between the allyl group in the carbene ligand and the adjacent norbornane moiety in the $\mathrm{P}^{*}$ ligand, which keeps the complex in conformations that lack an element of symmetry and prevents any dynamic process to equalize these methylene protons (vide infra).

(26) Antipas, A.; Buchler, J. W.; Gouterman, M.; Smith, P. D. J. Am. Chem. Soc. 1980, 102, 198.

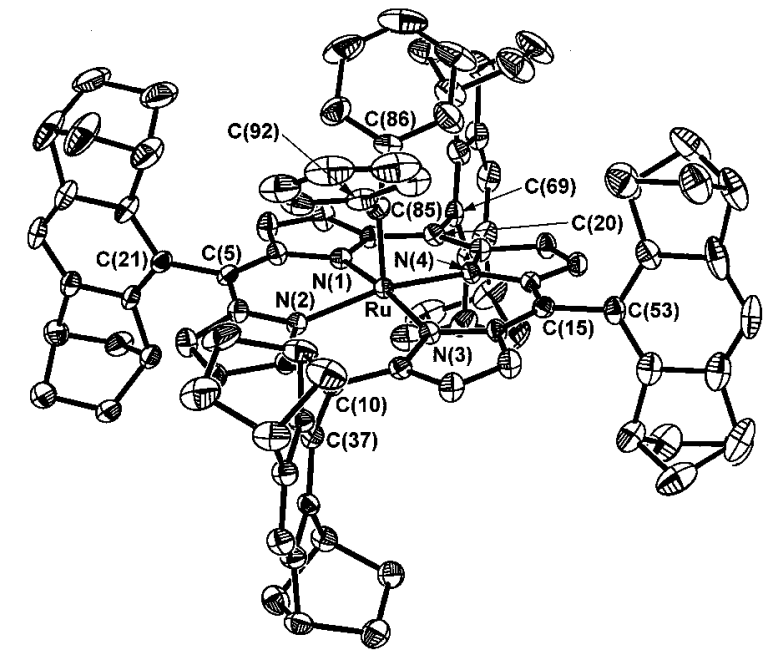

Figure 1. ORTEP drawing of $\mathbf{2} \cdot 2 \mathrm{CH}_{2} \mathrm{Cl}_{2}$ with thermal ellipsoids drawn at the $50 \%$ probability level. For clarity, the hydrogen atoms and solvent molecules are omitted, and only the numbering scheme for the key atoms is shown.

and $\mathbf{3}$ crystallized as $\mathbf{2} \cdot 2 \mathrm{CH}_{2} \mathrm{Cl}_{2}$ and $\mathbf{3} \cdot 3 \mathrm{CH}_{2} \mathrm{Cl}_{2}$, respectively, from a dichloromethane solution mixed with acetonitrile (2) and from dichloromethane/hexane exposed to the atmosphere (3). Table 4 summarizes the crystal data and structure refinement for both complexes; the structures are shown in Figures 1 and 2. Selected bond lengths ( $⿱$ A) and angles (deg) for $\mathbf{2}$ and $\mathbf{3}$ are listed in Table 5.

As shown in Figures 1 and 2 and Table 5, complexes 2 and 3 each contain a five-coordinate ruthenium atom that is situated in a slightly distorted square-pyramidal coordination sphere with the carbene $\mathrm{C}$ atom at the vertex site. This is different from the other structurally characterized metalloporphyrin carbene complexes, ${ }^{22,27}$ which are exclusively six-coordinate. Further, of the large number of structurally characterized mononuclear ruthenium porphyrins, ${ }^{22,24,28}$ complexes $\mathbf{2}$ and $\mathbf{3}$ belong to the few examples containing a five-coordinate ruthenium. 
Table 5. Selected Bond Lengths $(\AA)$ and Angles $(\mathrm{deg})$ for $\left[\mathrm{Ru}\left(\mathrm{P}^{*}\right)\left(\mathrm{CPh}_{2}\right)\right](\mathbf{2})$ and $\left[\mathrm{Ru}\left(\mathrm{P}^{*}\right)\left(\mathrm{C}(\mathrm{Ph}) \mathrm{CO}_{2} \mathrm{CH}_{2} \mathrm{CH}=\mathrm{CH}_{2}\right)\right](\mathbf{3})$

\begin{tabular}{|c|c|c|c|c|c|}
\hline & 2 & 3 & & 2 & 3 \\
\hline $\mathrm{Ru}-\mathrm{N}(1)$ & $2.037(5)$ & $2.039(2)$ & $\mathrm{Ru}-\mathrm{C}(85)$ & $1.860(6)$ & $1.847(3)$ \\
\hline $\mathrm{Ru}-\mathrm{N}(2)$ & $2.046(5)$ & $2.031(2)$ & $\mathrm{C}(85)-\mathrm{C}(86)$ & $1.499(9)$ & $1.460(4)$ \\
\hline $\mathrm{Ru}-\mathrm{N}(3)$ & $2.039(5)$ & $2.033(2)$ & $\mathrm{C}(85)-\mathrm{C}(92)$ & $1.496(9)$ & $1.496(4)$ \\
\hline \multirow[t]{2}{*}{$\mathrm{Ru}-\mathrm{N}(4)$} & $2.053(5)$ & $2.047(2)$ & & & \\
\hline & & & $\mathrm{C}(86)-\mathrm{C}(85)-\mathrm{C}(92)$ & $112.1(5)$ & $114.3(2)$ \\
\hline $\mathrm{Ru}-\mathrm{C}(85)-\mathrm{C}(86)$ & $124.3(5)$ & $127.1(2)$ & $\mathrm{Ru}-\mathrm{C}(85)-\mathrm{C}(92)$ & $123.7(5)$ & $118.3(2)$ \\
\hline $\mathrm{C}(85)-\mathrm{Ru}-\mathrm{N}(1)$ & $95.1(2)$ & $93.5(1)$ & $\mathrm{C}(85)-\mathrm{Ru}-\mathrm{N}(2)$ & $95.8(2)$ & $94.8(1)$ \\
\hline $\mathrm{C}(85)-\mathrm{Ru}-\mathrm{N}(3)$ & $93.8(2)$ & $94.6(1)$ & $\mathrm{C}(85)-\mathrm{Ru}-\mathrm{N}(4)$ & $97.1(2)$ & $102.1(1)$ \\
\hline $\mathrm{N}(1)-\mathrm{Ru}-\mathrm{N}(2)$ & $89.4(2)$ & $89.57(8)$ & $\mathrm{N}(2)-\mathrm{Ru}-\mathrm{N}(3)$ & $89.7(2)$ & $89.57(7)$ \\
\hline $\mathrm{N}(3)-\mathrm{Ru}-\mathrm{N}(4)$ & $89.5(2)$ & $88.75(7)$ & $\mathrm{N}(4)-\mathrm{Ru}-\mathrm{N}(1)$ & $89.5(2)$ & $89.75(7)$ \\
\hline $\mathrm{N}(1)-\mathrm{Ru}-\mathrm{N}(3)$ & $171.2(2)$ & $171.95(8)$ & $\mathrm{N}(2)-\mathrm{Ru}-\mathrm{N}(4)$ & $167.2(2)$ & $163.09(9)$ \\
\hline
\end{tabular}

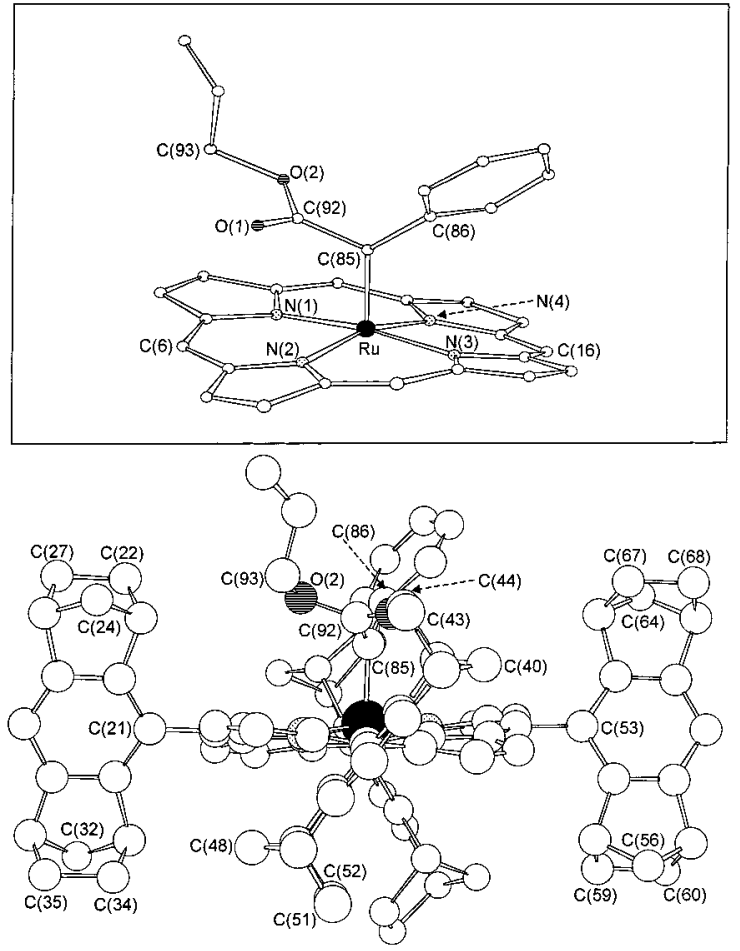

Figure 2. Ball and stick drawing of $3 \cdot 3 \mathrm{CH}_{2} \mathrm{Cl}_{2}$ with the atom-numbing scheme (viewed along the $\mathrm{C}(6)-\mathrm{C}(16)$ axis). The hydrogen atoms and solvent molecules are not shown. For clarity, the core structure of $\mathbf{3}$ is depicted in the inset.

In view of the presence of potentially coordinating acetonitrile or water in the solution from which the crystals $2 \cdot 2 \mathrm{CH}_{2} \mathrm{Cl}_{2}$ and $\mathbf{3} \cdot 3 \mathrm{CH}_{2} \mathrm{Cl}_{2}$ grew, the formation of $\mathbf{2}$ and $\mathbf{3}$ with a vacant axial site is astonishing. We note that a non-porphyrin ruthenium tetraaza[14] annulene complex, $\left[\mathrm{Ru}(\mathrm{tmtaa})\left(\mathrm{CPh}_{2}\right)\right](\mathbf{1 5}),{ }^{5 \mathrm{e}}$ with the same carbene group as in $\mathbf{2}$ recently reported by Floriani and co-workers ${ }^{23}$ also has a five-coordinate ruthenium atom.

Although the ruthenium atom in $\mathbf{2}$ has a coordination geometry similar to that in $\mathbf{1 5}$, the coordinated diphenylcarbene groups in $\mathbf{2}$ and $\mathbf{1 5}$ are considerably different in the following aspects. ${ }^{29}$ First, the carbene $\mathrm{C}(85), \mathrm{C}(86)$, and $\mathrm{C}(92)$ plane in 2

(27) (a) Mansuy, D.; Lange, M.; Chottard, J. C.; Bartoli, J. F.; Chevrier, B.; Weiss, R. Angew. Chem., Int. Ed. Engl. 1978, 17, 781. (b) Boschi, T.; Licoccia, S.; Paolesse, R.; Tagliatesta, P.; Pelizzi, G.; Vitali, F. Organometallics 1989, 8, 330. (c) Djukic, J.-P.; Smith, D. A.; Young, V. G., Jr.; Woo, L. K. Organometallics 1994, 13, 3020.

(28) (a) Ke, M.; Rettig, S. J.; James, B. R.; Dolphin, D. J. Chem. Soc., Chem. Commun. 1987, 1110. (b) Alexander, C. S.; Rettig, S. J.; James, B. R. Organometallics 1994, 13, 2542. (c) Sun, X.-R.; Huang, J.-S.; Cheung, K.-K.; Che, C.-M. Inorg. Chem. 2000, 39, 820 and references therein. (d) Au, S.-M.; Huang, J.-S.; Yu, W.-Y.; Fung, W.-H.; Che, C.-M. J. Am. Chem. Soc. 1999, 121, 9120. (e) Huang, J.-S.; Sun, X.-R.; Leung, S. K.-Y.; Cheung, K.-K.; Che, C.-M. Chem. Eur. J. 2000, 6, 334. (f) Huang, J.-S.; Leung, S. K.-Y.; Cheung, K.-K.; Che, C.-M. Chem. Eur. J. 2000, 6, 2971. lies almost halfway between the adjacent $\mathrm{Ru}-\mathrm{N}$ bonds (e.g., $\mathrm{Ru}-\mathrm{N}(2)$ and $\mathrm{Ru}-\mathrm{N}(3))$, whereas the corresponding plane in 15 is almost parallel to diagonal $\mathrm{Ru}-\mathrm{N}$ bonds. Second, the $\mathrm{C}(86)-\mathrm{C}(85)-\mathrm{C}(92)$ angle of $112.1(5)^{\circ}$ in $\mathbf{2}$ is appreciably smaller than the corresponding angle in $\mathbf{1 5}\left(116.4(6)^{\circ}\right)$. Third, the two phenyl groups basically adopt a "face-to-face" conformation in $\mathbf{2}$ but a "face-to-edge" conformation in $\mathbf{1 5}$.

The $\mathrm{Ru}-\mathrm{C}$ (carbene) distances of $1.860(6) \AA$ in 2 and $1.847(3) \AA$ in $\mathbf{3}$ are similar to or slightly shorter than that in $\mathbf{1 5}$ $(1.874(8) \AA)^{23}$ but slightly longer than that in $\mathbf{1 4}(1.829(9) \AA) .{ }^{22}$ The ruthenium atom is displaced from the mean plane of the four pyrrole nitrogens toward the carbene $\mathrm{C}$ atom by $\sim 0.19 \AA$ in 2 and $\sim 0.22 \AA$ in 3; both the displacements are larger than those reported for the five-coordinate ruthenium porphyrin alkyl $^{28 \mathrm{~b}}$ or aryl ${ }^{28 \mathrm{a}}$ complexes $(\sim 0.11 \AA)$ but smaller than that reported for $\mathbf{1 5}(\sim 0.37 \AA) .{ }^{23}$ As is evident from Figure 2 and Figure S4 (see Supporting Information), the porphyrin ring of either $\mathbf{2}$ or $\mathbf{3}$ exhibits an appreciable puckering distortion.

While the foregoing structural features of the diphenylcarbene complex $\mathbf{2}$ and the phenyl(allyloxycarbonyl)carbene complex 3 are similar, there is a marked change in the orientations of some meso phenyl groups of the $\mathrm{P}^{*}$ ligand on going from 2 to 3, accompanied by a change in the orientation of the carbene plane. ${ }^{30}$ Note the meso phenyl groups adjacent to the carbene ligand in 3 (Figure 2), which are severely distorted from the orientations basically perpendicular to the porphyrin ring observed in 2 (see Figure S4), probably to keep the fused norbornane moieties away from the carbene ligand. The $\mathrm{C}(85)$, $\mathrm{C}(86)$, and $\mathrm{C}(92)$ plane in 3 rotates $\sim 10^{\circ}$ toward the $\mathrm{Ru}-\mathrm{N}(1)$ bond from the position that bisects the $\mathrm{N}(1)-\mathrm{Ru}-\mathrm{N}(2)$ angle, different from the orientation of the corresponding plane in 2 described above.

Asymmetric Intermolecular Cyclopropanation Catalyzed by $\left[\mathbf{R u}\left(\mathbf{P}^{*}\right)\left(\mathbf{C} \mathbf{P h}_{2}\right)\right](\mathbf{2})$. Under conditions identical to those indicated in note a of Table 1, except using $\mathbf{2}$ instead of $\mathbf{1}$ as the catalyst, the results obtained for the cyclopropanation of terminal alkenes $\mathbf{4 a}-\mathbf{g}$ with EDA are shown in Table 6. As shown in this table, for all these alkene substrates, the complex 2-catalyzed cyclopropanations afforded cyclopropyl esters $\mathbf{6}$ and 7 in moderate to good yields $(36-75 \%)$. The trans/cis ratios

(29) This probably stems from different steric interactions of the carbene group with the porphyrin and tetraaza[14]annulene ligands.

(30) We think that these orientation changes are due to the steric interaction in $\mathbf{3}$ between the allyl group (rather than the phenyl group) of the carbene ligand and the adjacent norbornane moiety of the $\mathrm{P}^{*}$ ligand, since the orientations of the carbene plane and meso phenyl groups in the diphenylcarbene complex $\mathbf{2}$ are quite normal. Indeed, inspection of the space filling model of $\mathbf{3}$ reveals that the rotations of the allyloxycarbonyl group about any of the $\mathrm{C}(93)-\mathrm{O}(2), \mathrm{O}(2)-\mathrm{C}(92)$, and $\mathrm{C}(92)-\mathrm{C}(85)$ bonds are rather limited whereas the rotation of the carbene phenyl group about the $\mathrm{C}(85)-\mathrm{C}(86)$ bond is relatively free. This finding, together with the lack of symmetry in the structure of $\mathbf{3}$ (Figure 2), should account for the unusual $\mathrm{OCH}_{2}$ but normal phenyl signal patterns described earlier for the $\mathrm{C}(\mathrm{Ph})$ $\mathrm{CO}_{2} \mathrm{CH}_{2} \mathrm{CH}=\mathrm{CH}_{2}$ group in the ${ }^{1} \mathrm{H}$ NMR spectrum of 3 . 
Table 6. Asymmetric Cyclopropanation of Styrene and Its Derivatives with Ethyl Diazoacetate (5a) Catalyzed by $\left[\mathrm{Ru}\left(\mathrm{P}^{*}\right)\left(\mathrm{CPh}_{2}\right)\right](\mathbf{2})^{a}$

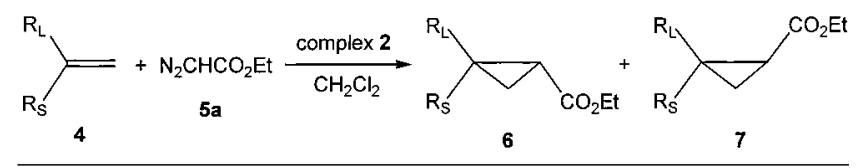

\begin{tabular}{|c|c|c|c|c|c|c|c|c|}
\hline \multirow[b]{2}{*}{ entry } & \multicolumn{3}{|c|}{$\begin{array}{c}\text { substrate (4) } \\
\left(\mathrm{R}_{\mathrm{L}}=p-\mathrm{X}-\mathrm{C}_{6} \mathrm{H}_{4}\right) \\
\end{array}$} & \multirow{2}{*}{$\begin{array}{l}\text { yield }(\%) \\
(6+7)\end{array}$} & \multirow{2}{*}{$\begin{array}{c}\operatorname{trans} / \text { cis ratio } \\
(6 / 7)\end{array}$} & \multicolumn{2}{|c|}{$\%$ ee } & \multirow{2}{*}{$\begin{array}{l}\text { turnovers } \\
\text { (2) }\end{array}$} \\
\hline & & $\mathrm{R}_{\mathrm{S}}$ & $\mathrm{X}$ & & & 6 & $\overline{7}$ & \\
\hline 1 & $4 a$ & $\mathrm{H}$ & $\mathrm{H}$ & 36 & 11 & 83 & 7 & $7.2 \times 10^{2}$ \\
\hline 2 & $4 b$ & $\mathrm{Ph}$ & $\mathrm{H}$ & 63 & & 70 & & $1.3 \times 10^{3}$ \\
\hline 3 & $4 c$ & $\mathrm{Me}$ & $\mathrm{H}$ & 72 & 5.6 & 66 & 25 & $1.4 \times 10^{3}$ \\
\hline 4 & $4 d$ & $\mathrm{H}$ & $\mathrm{Cl}$ & 61 & 5.2 & 88 & 40 & $1.2 \times 10^{3}$ \\
\hline 5 & $4 e$ & $\mathrm{H}$ & $\mathrm{F}$ & 71 & 8.4 & 85 & 12 & $1.4 \times 10^{3}$ \\
\hline 6 & $4 f$ & $\mathrm{H}$ & $\mathrm{Me}$ & 62 & 4.1 & 71 & nd & $1.2 \times 10^{3}$ \\
\hline 7 & $4 \mathrm{~g}$ & $\mathrm{H}$ & $\mathrm{MeO}$ & 75 & 12 & 71 & 9 & $1.5 \times 10^{3}$ \\
\hline
\end{tabular}

${ }^{a}$ Reaction conditions and the configurations of 6 are the same as indicated in Table 1.

(up to 12) and the enantiocontrol (up to $88 \%$ ee for the trans isomers 6) are relatively high. However, compared with complex $\mathbf{1}$, complex $\mathbf{2}$ is a less selective catalyst for reaction 1, especially in terms of trans selectivity (cf. Tables 1 and 6).

To our knowledge, $\mathbf{2}$ is the first structurally characterized chiral metal carbene complex that acts as an efficient catalyst for asymmetric cyclopropanation of alkenes. Prior to this work, Nishiyama and co-workers demonstrated that a structurally characterized chiral carbene complex $\left[\mathrm{Ru}(\right.$ pybox $) \mathrm{Cl}_{2}\left(\mathrm{C}\left(\mathrm{CO}_{2}-\right.\right.$ Et) $)_{2}$ )] undergoes stoichiometric asymmetric alkene cyclopropanation at $110{ }^{\circ} \mathrm{C} .4 \mathrm{~d}$

The fact that the monocarbene complex $\mathbf{2}$ can efficiently catalyze reaction 1 but is inert toward stoichiometric alkene cyclopropanation spurred our interest in examining the catalytic process in some detail. When the cyclopropanation of styrene with EDA in the presence of a catalytic amount of $\mathbf{2}$ was monitored by UV-vis spectroscopy and GC-MS, we found complex 2 sustained not less than 200 turnovers, suggesting that the monocarbene entity remains intact during this period in the catalytic reaction.

\section{Discussion}

Development of Metalloporphyrin Cyclopropanation Catalysts. The utilization of metalloporphyrins as catalysts for intermolecular alkene cyclopropanation is traced back to 1980 , when Callot and co-workers ${ }^{31}$ reported that rhodium(III) porphyrins catalyze the EDA cyclopropanation of common alkenes in $60-71 \%$ yields with an intriguing cis selectivity, contrary to the trans selectivity generally observed for the classical nonporphyrin cyclopropanation catalysts. Trans-selective metalloporphyrin cyclopropanation catalysts were first developed by Woo and co-workers for osmium porphyrins ${ }^{32}$ and later by Kodadek and Woo for iron porphyrins. ${ }^{16}$ However, since the porphyrin macrocycles in these catalysts bear no chiral auxiliaries, the resultant cyclopropanation reactions are not enantioselective. $^{33}$

There are a wide variety of chiral metalloporphyrins known in the literature, ${ }^{34}$ whose catalytic behavior toward asymmetric alkene epoxidation has been examined. Yet few of them were

(31) Callot, H. J.; Piechocki, C. Tetrahedron Lett. 1980, 21, 3489.

(32) Smith, D. A.; Reynolds, D. N.; Woo, L. K. J. Am. Chem. Soc. 1993, $115,2511$.

(33) Gross and co-workers recently reported that nonchiral iron, ruthenium, osmium, and rhodium porphyrins can catalyze asymmetric cyclopropanation of styrene with a chiral carbenoid, see: Gross, Z.; Galili, N.; Simkhovich, L. Tetrahedron Lett. 1999, 40, 1571. utilized as catalysts for asymmetric intermolecular cyclopropanation reactions, as already described in the Introduction.

On the other hand, the asymmetric intramolecular cyclopropanation depicted as reaction 2 in Scheme 1 was investigated extensively in recent years. . $^{1,4 b, 18,35-37}$ Currently, the most selective catalyst for this reaction is the dirhodium(II) carboxamidate complex developed by Doyle and co-workers. ${ }^{18,35}$ Despite the advantage that such intramolecular reactions usually afford only one diastereomer because of geometric constraints ${ }^{18}$ (unlike the intermolecular reaction 1 in which diastereocontrol is an important issue), prior to this work the use of a metalloporphyrin catalyst for an intramolecular alkene cyclopropanation remains essentially unexplored. ${ }^{38}$

Following our preliminary work that demonstrates the efficiency of the chiral carbonylruthenium(II) porphyrin complex $\mathbf{1}$ in catalyzing reaction 1 for a series of terminal alkenes, ${ }^{9}$ the present one addresses a number of issues including the effects of temperature, catalyst loading, solvent, diazoacetate, and alkene on the reaction. Moreover, it demonstrates the feasibility of using complex $\mathbf{1}$ as an efficient catalyst for reaction 2 . Although the enantioselectivity in reaction 2 obtained for catalyst 1 is not superior to that for the foregoing dirhodium(II) carboxamidate catalyst, the present work first demonstrates the efficiency of a chiral metalloporphyrin in catalyzing asymmetric intramolecular cyclopropanations.

The results shown in entry 3 of Table 1 (ee 98\%, trans/cis ratio 36) represent the highest selectivity yet obtained for complex 1-catalyzed reaction 1 , which to our knowledge also represent the highest diastereocontrol ever attained for metal complex-catalyzed cyclopropanation of styrene with EDA, whose trans product $\mathbf{6} \mathbf{a}$ is a critical precursor for the synthesis of tranylcypromine (an oral MAOI-type antidepressant). ${ }^{39}$ The unusual robustness of catalyst 1 is reflected by the $1.1 \times 10^{4}$ turnovers shown in entry 4 of Table 1 , a value unprecedentedly high for metal complex-catalyzed cyclopropanations.

On the Nature of the Active Intermediates in $[R u(P *)$ (CO)(EtOH)] (1)-Catalyzed Inter- and Intramolecular Cyclopropanations. In the literature, it is widely believed that the active intermediates in metal-catalyzed inter- and intramolecular cyclopropanations of alkenes are electrophilic metal carbene complexes, ${ }^{1}$ a few of which have eventually been isolated in the case of intermolecular systems by treating the catalysts with the respective diazoacetates in the absence of alkenes..$^{4 c, d, 32}$ The isolation of carbenoid intermediates in the intramolecular systems seems more challenging owing to the required coexistence of the carbene moiety and the pendant alkene group, and has not been realized so far.

(34) Collman, J. P.; Zhang, X.; Lee, V. J.; Uffelman, E. S.; Brauman, J. I. Science 1993, 261, 1404 .

(35) (a) Doyle, M. P.; Pieters, R. J.; Martin, S. F.; Austin, R. E.; Oalmann, C. J.; Müller, P. J. Am. Chem. Soc. 1991, 113, 1423. (b) Doyle, M. P.; Zhou, Q.-L.; Dyatkin, A. B.; Ruppar, D. A. Tetrahedron Lett. 1995, 36, 7579. (c) Doyle, M. P.; Peterson, C. S.; Zhou, Q.-L.; Nishiyama, H. Chem. Commun. 1997, 211. (d) Doyle, M. P.; Davies, S. B.; Hu, W. Org. Lett. 2000, 2, 1145. (e) Doyle, M. P.; Hu, W.; Chapman, B.; Marnett, A. B.; Peterson, C. S.; Vitale, J. P.; Stanley, S. A. J. Am. Chem. Soc. 2000, 122, 5718 .

(36) (a) Martin, S. F.; Oalmann, C. J.; Liras, S. Tetrahedron Lett. 1992, 33, 6727. (b) Martin, S. F.; Oalmann, C. J.; Liras, S. Tetrahedron 1993, 49, 3521 . 941.

(38) Kodadek and co-workers investigated the rhodium porphyrincatalyzed reaction 2 for cis-5-methyl-2-hexenyl diazoacetate, which afforded the cyclopropyl lactone in $10 \%$ ee. The yield of the product was not reported. See: Maxwell, J. L.; O’Malley, S.; Brown, K. C.; Kodadek, T. Organometallics 1992, 11, 645.

(39) Csuk, R.; Schabel, M. J.; von Scholz, Y. Tetrahedron: Asymmetry 1996, 7, 3505 . 
Concerning metalloporphyrin-catalyzed alkene cyclopropanations, previous studies on rhodium, ${ }^{7,12,31}$ osmium,,${ }^{32}$ iron, ${ }^{16}$ and ruthenium $^{13}$ catalysts all support the intermediacy of the respective metalloporphyrin carbene complexes in the processes. Notably, Woo and co-workers successfully isolated a nonchiral osmium porphyrin monocarbene complex that can undergo catalytic alkene cyclopropanation reactions. ${ }^{32}$

The active intermediates in complex 1-catalyzed reactions 1 and 2 have not been isolated and clearly identified despite multiple attempts. However, insight into the nature of these intermediates can be obtained from the foregoing results on the solvent and substitutent effects on complex 1-catalyzed reaction 1 , from the observed reactivity of complex 1 toward diazoacetates, and from the catalytic behavior of complex $\mathbf{2}$ toward reaction 1 .

The solvent effect reflects some similarity between the active intermediates in the complex 1- and iron porphyrin-catalyzed intermolecular cyclopropanations. In the latter system, the putative monocarbene active intermediate $\left[\mathrm{Fe}(\mathrm{Por})\left(\mathrm{CHCO}_{2} \mathrm{Et}\right)\right]$ capable of binding donor solvents in an axial site accounts for the increase of trans selectivity with increasing donating capability of the solvent. ${ }^{16}$ However, the opposite trends of trans selectivity from diethyl ether to tetrahydrofuran for the iron porphyrin- and complex 1-catalyzed cyclopropanations may imply that the active intermediates in complex 1-catalyzed reaction 1 are not simply a ruthenium counterpart of [Fe(Por)$\left.\left(\mathrm{CHCO}_{2} \mathrm{Et}\right)\right]$, i.e., the five-coordinate monocarbene species [Ru$\left.\left(\mathrm{P}^{*}\right)\left(\mathrm{CHCO}_{2} \mathrm{R}\right)\right]$.

The substituent effect suggests a more rapid cyclopropanation for more electron rich alkenes, a phenomenon typical for the cyclopropanations via electrophilic metal carbene intermediates. ${ }^{1}$ The linear correlation between $\log \left(k_{\mathrm{X}} / k_{\mathrm{H}}\right)$ and $\sigma^{+}$with a small negative $\rho^{+}$value $(-0.44 \pm 0.09)$ implies that the vinyl carbons of the styrenes in the rate-limiting transition state come into direct resonance interaction with the para substituents and may have some carbocationic character, which, however, should be far from a well-developed carbonium ion, since for reactions that involve a carbocation intermediate a large negative $\rho^{+}$value, such as the $\rho^{+}$of -4.54 found for the solvolysis of tert-cumyl chloride, ${ }^{40}$ is expected.

The reaction of complex 1 with diazoacetates $\mathbf{1 1}$ and $\mathbf{1 2}$ to form the respective five-coordinate carbene complexes [Ru$\left.\left(\mathrm{Por}^{*}\right)\left(\mathrm{CPh}_{2}\right)\right](2)$ and $\left[\mathrm{Ru}(\mathrm{P} *)\left(\mathrm{C}(\mathrm{Ph}) \mathrm{CO}_{2} \mathrm{CH}_{2} \mathrm{CH}=\mathrm{CH}_{2}\right)\right](3)$, together with reaction 6 which forms the six-coordinate complex $\mathbf{1 4}^{22}$ (see Scheme 2), reveals the possible formation of a chiral ruthenium carbene porphyrin, $\left[\mathrm{Ru}\left(\mathrm{P}^{*}\right)(\mathrm{CHX})\right]$ or $\left[\mathrm{Ru}\left(\mathrm{P}^{*}\right)\right.$ $(\mathrm{CHX})(\mathrm{L})]\left(\mathrm{X}=\mathrm{CO}_{2} \mathrm{R}\right.$ 16, $\left.\mathrm{CO}_{2}\left(\mathrm{CH}_{2}\right)_{n} \mathrm{C}\left(\mathrm{R}^{\mathrm{p}}\right)=\mathrm{CR}^{\mathrm{c}} \mathrm{R}^{\mathrm{t}} \mathbf{1 7}\right)$, in the catalytic systems " $\mathbf{1}+$ diazoacetate $\mathbf{5}+$ alkene $\mathbf{4}$ " or " $\mathbf{1}+$ diazoacetate $\mathbf{8}$ or $\mathbf{1 0}$ ". The inertness of the isolated fivecoordinate complexes $\mathbf{2}$ and $\mathbf{3}$ toward stoichiometric inter- or intramolecular alkene cyclopropanation at even $>100{ }^{\circ} \mathrm{C}$ suggests that either (i) the five-coordinate monocarbene species $\left[\mathrm{Ru}\left(\mathrm{P}^{*}\right)(\mathrm{CHX})\right]$ are not the active intermediates in complex 1-catalyzed reactions 1 and 2 (which can be conducted at temperatures of -40 to $\sim 20{ }^{\circ} \mathrm{C}$ ) or (ii) complexes 2 and $\mathbf{3}$ are much less reactive than $\left[\mathrm{Ru}\left(\mathrm{P}^{*}\right)(\mathrm{CHX})\right]$.

The catalytic behavior of complex 2 toward reaction 1 (i.e., significantly lower diastereocontrol than catalyst $\mathbf{1}$, cf. Tables 1 and 6) signifies the functioning of different active intermediates in the complex 1- and 2-catalyzed intermolecular cyclopropanations. Both catalysts, however, feature trans selectivity and have roughly comparable enantiocontrol. In view of the inertness of $\mathbf{2}$ toward stoichiometric cyclopropanation of styrene

(40) Brown, H. C.; Okamoto, Y. J. Am. Chem. Soc. 1958, 80, 4979. and the sustentation of $>200$ turnovers for $\mathbf{2}$ in the corresponding catalytic process, the $\left[\mathrm{Ru}\left(\mathrm{P}^{*}\right)\left(\mathrm{CPh}_{2}\right)\left(\mathrm{CHCO}_{2} \mathrm{Et}\right)\right](18)$ active intermediate bearing mixed carbene ligands is suggested in the complex 2-catalyzed cyclopropanations. Owing to $\mathrm{Ru}-\mathrm{C}$ multiple bonding, the carbene group $\mathrm{CPh}_{2}$ in $\mathbf{1 8}$ would have a strong trans effect, leading to weakening and hence increasing the reactivity of the $\mathrm{Ru}=\mathrm{CHCO}_{2}$ Et bond. Previously, Woo and coworkers $^{41}$ proposed osmium analogues of $\mathbf{1 8}$ as intermediates in the formation of alkenes catalyzed by nonchiral osmium porphyrins.

On the basis of these observations, we propose that the active intermediates in complex 1-catalyzed reactions 1 and 2 could be the respective ruthenium porphyrin carbene complexes [Ru$\left.\left(\mathrm{P}^{*}\right)(\mathrm{CHX})(\mathrm{L})\right](\mathbf{1 6}$ or 17$)$, where $\mathrm{L}$ is a ligand with a considerable trans effect, such as the carbene group $\mathrm{CHX} .{ }^{42} \mathrm{We}$, however, cannot exclude the possibility of the five-coordinate complexes $\left[\mathrm{Ru}\left(\mathrm{P}^{*}\right)(\mathrm{CHX})\right]$ and their adducts with solvent molecules acting as an active intermediate in these reactions. The lower trans selectivity and enantioselectivity in the EDA cyclopropanation of styrenes catalyzed by complex $\mathbf{2}$ than by complex 1 may be ascribed to different L ligands trans to the $\mathrm{CHCO}_{2} \mathrm{Et}$ group of the active intermediates in the two cases. Currently, it is uncertain how the intermediates $\mathbf{1 6}$ interact with donor solvents, such as ethers, to afford higher trans selectivity.

Bearing in mind the hitherto unrealized isolation of metal carbene intermediates in metal-catalyzed reaction 2 , the isolation of complex 3 , which contains a carbene group with a pendant $\mathrm{C}=\mathrm{C}$ bond and closely resembles the proposed intermediates 17 in complex 1-catalyzed reaction 2, is of interest. We know of no other examples of metalloporphyrin carbene complexes that have this property.

Scheme 3 shows the mechanism we propose here for the intermolecular cyclopropanation catalyzed by complex $\mathbf{1}$, in which the transition states for carbene transfer $19 \mathbf{a}$ and $19 b$ are presumed to be late and have parallel $\mathrm{C}=\mathrm{C}$ and $\mathrm{Ru}=\mathrm{C}$ bonds, analogous to their iron counterparts proposed by Kodadek, Woo, and co-workers. ${ }^{16}$ Apparently, the transition state 19a would be more stable than $\mathbf{1 9 b}$ due to the lack of steric interaction between the larger group $\left(\mathrm{R}_{\mathrm{L}}\right)$ on the alkene and the $\mathrm{CO}_{2} \mathrm{R}$ group on the carbene. Therefore, trans cyclopropanes are preferentially formed. ${ }^{43}$ It can be expected that a smaller $\mathrm{R}$ group in $\mathrm{CO}_{2} \mathrm{R}$ or a smaller difference in size between $R_{L}$ and $R_{S}$ groups would result in a lower trans/cis ratio, which is indeed the case in view of the trans selectivity order $\mathbf{5 b}<\mathbf{5 a}<\mathbf{5 c}$ (Table 2) and the much lower trans/cis ratio obtained for $\alpha$-methylstyrene (4c) than for the other styrenes (Table 1). Moreover, probably since it is difficult for nonterminal alkenes to reach a transition state similar to $\mathbf{1 9 a}$ and $\mathbf{1 9 b}$, such alkenes are found to be inferior

(41) Woo, L. K.; Smith, D. A. Organometallics 1992, 11, 2344.

(42) Although we were unable to directly observe any of the bis(carbene) species $\left[\mathrm{Ru}\left(\mathrm{P}^{*}\right)(\mathrm{CHX})_{2}\right]$, the formation of such species in the corresponding catalytic systems is not impossible. Previous work by Woo and co-workers indicates that a monocarbene osmium porphyrin $\left[\mathrm{Os}(\mathrm{TTP})\left(\mathrm{C}\left(p-\mathrm{C}_{6} \mathrm{H}_{4} \mathrm{Me}\right)_{2}\right)\right]$ can react with diaryldiazomethane $\mathrm{N}_{2} \mathrm{C}\left(p-\mathrm{C}_{6} \mathrm{H}_{4} \mathrm{Me}\right)_{2}$ to form a biscarbene complex [Os(TTP) $\left.\left(\mathrm{C}\left(p-\mathrm{C}_{6} \mathrm{H}_{4} \mathrm{Me}\right)_{2}\right)_{2}\right]$ (refs $5 \mathrm{f}$ and 41$)$. This implies that similar phenomenon may also occur with ruthenium owing to the analogy between the chemistry of osmium and ruthenium, which is to some extent supported by the possible formation of $\left[\mathrm{Ru}\left(\mathrm{P}^{*}\right)\left(\mathrm{CPh}_{2}\right)\left(\mathrm{CHCO}_{2} \mathrm{Et}\right)\right](\mathbf{1 8})$ in complex 2-catalyzed reaction 1. Moreover, Simonneaux and co-workers (ref 22) observed that the EDA cyclopropanations of styrene catalyzed by nonchiral complexes $\left[\mathrm{Ru}(\mathrm{TPP})\left(\mathrm{C}\left(\mathrm{CO}_{2} \mathrm{Et}\right)_{2}\right)(\mathrm{MeOH})\right](\mathbf{1 4})$ and $[\mathrm{Ru}(\mathrm{TPP})$ $(\mathrm{CO})(\mathrm{EtOH})]$ afford similar trans/cis ratios and in the former case the final ruthenium-containing products are basically the original carbene complex. In our opinion this observation, together with the fact that the $\mathrm{C}\left(\mathrm{CO}_{2} \mathrm{Et}\right)_{2}$ group in $\mathbf{1 4}$ is rather inert but the $\mathrm{CO}$ group in $[\mathrm{Ru}(\mathrm{TPP})(\mathrm{CO})(\mathrm{EtOH})]$ labile toward the attack by EDA to form $\left[\mathrm{Ru}(\mathrm{TPP})\left(\mathrm{CHCO}_{2} \mathrm{Et}\right)\right]$, possibly implies the intermediacy of $\left[\mathrm{Ru}(\mathrm{TPP})\left(\mathrm{C}\left(\mathrm{CO}_{2} \mathrm{Et}\right)_{2}\right)\left(\mathrm{CHCO}_{2} \mathrm{Et}\right)\right]$ in the case of catalyst 14 (although this possibility is not mentioned in that paper). 


\section{Scheme 3}

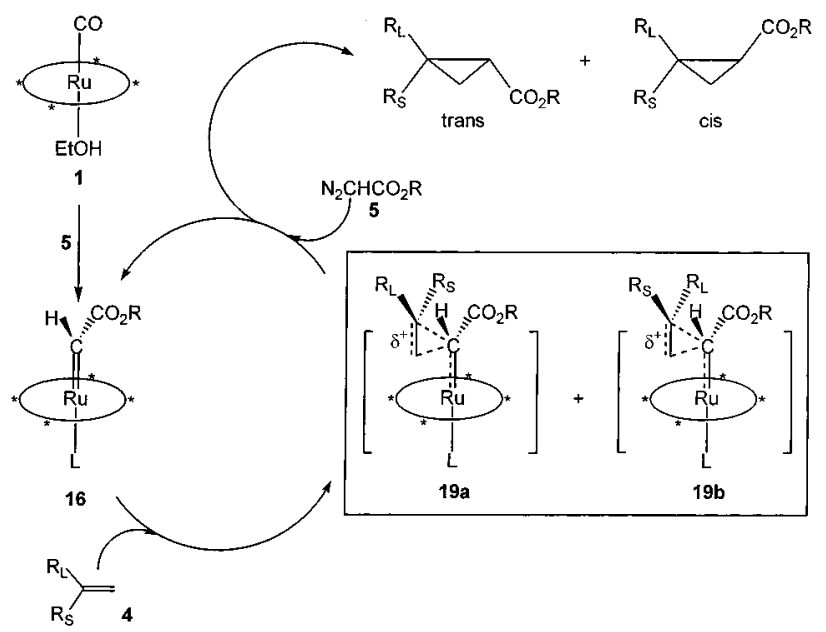

substrates for the ruthenium porphyrin-catalyzed intermolecular cyclopropanation. ${ }^{14}$

Rationalization of the Enantioselectivity in $\left[\mathbf{R u}\left(\mathbf{P}^{*}\right)(\mathbf{C O})-\right.$ (EtOH)] (1)-Catalyzed Inter- and Intramolecular Cyclopropanations. The understanding of enantiocontrol in complex 1-catalyzed reactions 1 and 2 is of fundamental importance for the further development of this type of catalyst. Suppose that $\mathbf{1 6}$ or $\mathbf{1 7}$ are really the active intermediates in these processes, a key step for rationalizing the observed enantioselectivity is to determine the conformation of the sterically demanding $\mathrm{P}^{*}$ ligand and the orientation of the carbene plane with respect to the macrocycle in these chiral intermediates. Since intermediates 16 and 17 bear the same $D_{4}$-symmetric porphyrin ligand in the same absolute configuration as complexes $\mathbf{2}$ and $\mathbf{3}$ and all the species 16, 17, 2, and 3 are ruthenium porphyrin carbene complexes, the structural information on $\mathbf{2}$ and $\mathbf{3}$ serves as a useful basis for rationalizing the enantioselectivity in complex 1-catalyzed reactions 1 and $2 .^{44}$

(i) Intermolecular Cyclopropanation. As shown in Table 1, complex 1-catalyzed reaction 1 for styrene (substrate $\mathbf{4 a}$ ) affords the predominant, trans isomer $\mathbf{6 a}$ in high enantioselectivity. To rationalize the enantiocontrol for this substrate, we

(43) As one reviewer pointed out, although the steric inspection rationalizes the trans selectivity for catalyst $\mathbf{1}$, the electronic factor, i.e., the ruthenium metal, may be primarily responsible for the extraordinary trans selectivity for the ruthenium catalyst. This is reflected in the proposed late transition states $(\mathbf{1 9 a}, \mathbf{b})$ in Scheme 3, which contrast with the early transition state in rhodium porphyrin catalysts. Indeed, in addition to the ruthenium-pybox and ruthenium porphyrin catalysts described in the text, other reported ruthenium cyclopropanation catalysts also exhibit a trans selectivity, see for example: (a) Simal, F.; Demonceau, A.; Noels, A. F. Tetrahedron Lett. 1998, 39, 3493. (b) Simal, F.; Jan, D.; Demonceau, A. Noels, A. F. Tetrahedron Lett. 1999, 40 1653. (c) Stoop, R. M.; Bauer, C.; Setz, P.; Wörle, M.; Wong, T. Y. H.; Mezzetti, A. Organometallics 1999, 18, 5691. (d) Bianchini, C.; Lee, H. M. Organometallics 2000, 19, 1833 , and references in these papers. An obvious exception is the rutheniumsalen catalyst reported by Katsuki and co-workers (Uchida, T.; Irie, R.; Katsuki, T. Tetrahedron 2000, 56, 3501), which shows a cis selectivity.

(44) Since the identity of $\mathrm{L}$ in $\left[\mathrm{Ru}\left(\mathrm{P}^{*}\right)(\mathrm{CHX})(\mathrm{L})\right](\mathbf{1 6}$ and 17) remains open, the following are to be considered about the structures of these proposed intermediates. When $\mathrm{L} \neq \mathrm{CHX}, \mathbf{1 6} / \mathbf{1 7}$ are monocarbene species and would have a $\left[\mathrm{Ru}\left(\mathrm{P}^{*}\right)(\mathrm{CHX})\right]$ moiety similar to complex $2 / 3$. If $\mathrm{L}=$ $\mathrm{CHX}$, i.e., 16/17 are biscarbene species $\left[\mathrm{Ru}\left(\mathrm{P}^{*}\right)(\mathrm{CHX})_{2}\right]$, then it may not always be the case that both the carbene ligands coordinate to the ruthenium center in the same manner as those in $\mathbf{2 / 3}$. However, according to theoretical studies on trans-biscarbene complexes (see for example: Albright, T. A.; Burdett, J. K.; Whangbo, M. H. In Orbitals Interactions in Chemistry; Wiley: New York, 1985; p 286. Cauchy, D.; Jean, Y.; Eisenstein, O.; Volatron, F. Organometallics 1988, 7, 829), the two carbene planes will preferentially be orthogonal to each other. In this case, the rationalization of enantioselectivity on the basis of either of the CHX groups gives the same results owing to the $D_{4}$-symmetric nature of the $\mathrm{P}^{*}$ macrocycle.
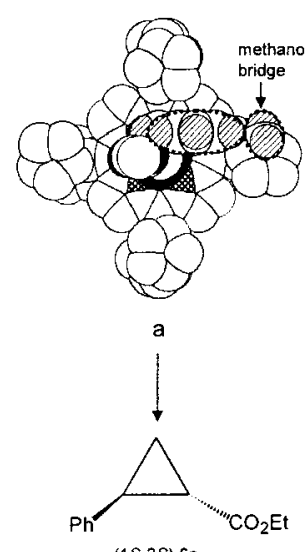

(1S, 2S)-6a
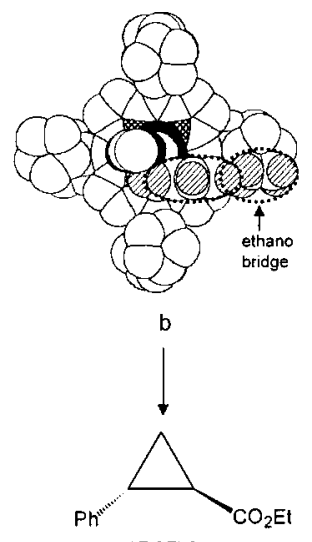

$(1 R, 2 R)-6 \mathbf{a}$
Figure 3. Top-view space-filling model for the $\left[\mathrm{Ru}\left(\mathrm{P}^{*}\right)\left(\mathrm{CHCO}_{2} \mathrm{R}\right)\right]$ moiety $(\mathrm{R}=\mathrm{Et})$ of the proposed active species $\mathbf{1 6}$ on the basis of the $\mathrm{X}$-ray structure of complex $\mathbf{2}$ and the interaction of its carbene group with styrene placed (a) above and (b) below the carbene plane. Hydrogen atoms are not shown except those in styrene and the indicated methano and ethano bridges.

built a model for the key moiety $\left[\mathrm{Ru}\left(\mathrm{P}^{*}\right)\left(\mathrm{CHCO}_{2} \mathrm{R}\right)\right](\mathrm{R}=\mathrm{Et})$ of the proposed active intermediate $\mathbf{1 6}$ (Figure 3 ) by employing the CS Chem 3D 4.5 software package, with the P* geometry and carbene plane orientation the same as those in the structure of the ruthenium carbene complex 2. A styrene molecule oriented as in the transition state 19a (Scheme 3) was placed above (Figure 3a) and below (Figure 3b) the carbene plane (corresponding to the transition states that produce the trans cyclopropane in $(1 S, 2 S)$ and $(1 R, 2 R)$ configuration, respectively). Evidently, the interaction between the styrene phenyl group and the sterically demanding ethano bridge of the norbornane moiety in Figure $3 \mathrm{~b}$ will provoke a severe strain. Therefore, the transition state corresponding to Figure $3 \mathrm{a}$ is greatly preferred over that corresponding to Figure $3 \mathrm{~b}$. This accounts for the high ee's attained for $\mathbf{6 a}$ with its predominant enantiomer in the $(1 S, 2 S)$ configuration (see note e in Table 1).

Similar rationalization may be applicable to the cases of the substrates $\mathbf{4} \mathbf{c}-\mathbf{g}$ in Table 1 . Worthy of note is the good enantiocontrol for substrate 1,1-diphenylethene (4b). If the terminal $\mathrm{C}=\mathrm{C}$ bond of $\mathbf{4 b}$ is fully parallel to the $\mathrm{Ru}=\mathrm{C}$ bond in the transition state, the resulting cyclopropanation is expected to be nonenantioselective according to the above rationalization, which is contrary to the results shown in Table 1. We think that for this alkene, to ease the steric interaction between the alkene phenyl group and the carbene ethoxycarbonyl group, the terminal $\mathrm{C}=\mathrm{C}$ bond may preferably tilt toward the methano bridge indicated in Figure $3 \mathrm{a}$, thus accounting for the observed predominant $(S)$-configuration.

(ii) Intramolecular Cyclopropanation. The results of complex 1-catalyzed reaction 2 manifest that allylic diazoacetates $\mathrm{N}_{2} \mathrm{CHCO}_{2} \mathrm{CH}_{2} \mathrm{CH}=\mathrm{CR}^{\mathrm{c}} \mathrm{R}^{\mathrm{t}}(\mathbf{8} \mathbf{a}-\mathbf{d})$ are superior substrates for this catalytic system. Since for substrate $\mathbf{8 c}$ the absolute configuration of the resultant cyclopropyl lactone $9 \mathrm{c}$ was not determined, the enantioselectivity rationalization here will be confined to substrates $\mathbf{8 a}, \mathbf{b}, \mathbf{d}$. In these cases, the proposed intermediates are $\left[\mathrm{Ru}\left(\mathrm{P}^{*}\right)\left(\mathrm{CHCO}_{2} \mathrm{CH}_{2} \mathrm{CH}=\mathrm{CR}^{\mathrm{c}} \mathrm{R}^{\mathrm{t}}\right)(\mathrm{L})\right]{ }^{44}$

As described earlier, the structure of $\mathbf{3}$ features an appreciable distortion of the $C(85), C(86)$, and $C(92)$ plane from the position bisecting the $\mathrm{N}(1)-\mathrm{Ru}-\mathrm{N}(2)$ angle and a severe distortion of some meso phenyl rings from being perpendicular to the porphyrin ring, probably due to a considerable steric interaction between the allyl group and the adjacent norbornane moiety. ${ }^{30}$ A similar phenomenon most likely occurs with the $\left[\mathrm{Ru}\left(\mathrm{P}^{*}\right)\right.$ $\left.\left(\mathrm{CHCO}_{2} \mathrm{CH}_{2} \mathrm{CH}=\mathrm{CR}^{\mathrm{c}}{ }^{\mathrm{t}}\right)\right]$ moieties. 


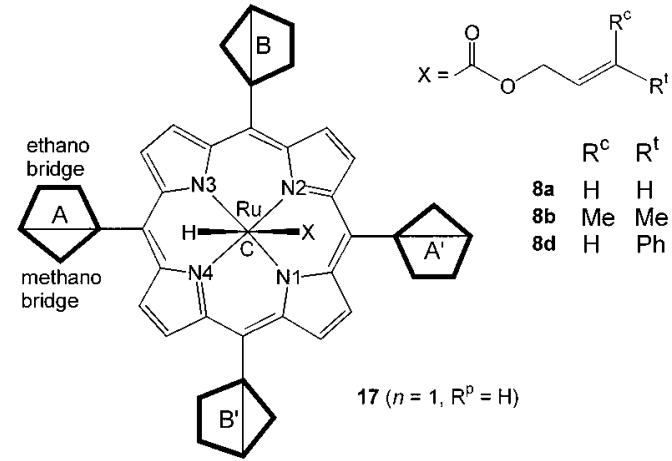

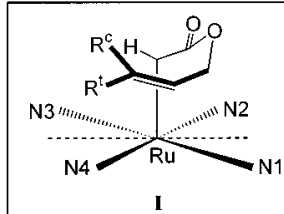
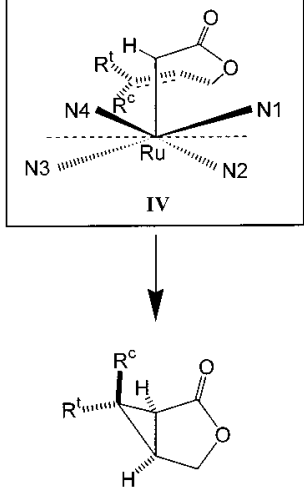

$(1 R, 5 S)-9 \mathrm{a}, \mathbf{d},(1 S, 5 R)-9 \mathrm{~b}$

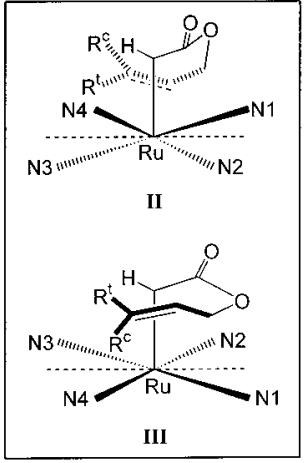

$\downarrow$

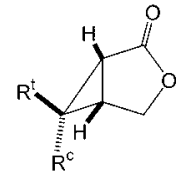

$(1 S, 5 R)-9 \mathrm{a}, \mathrm{d},(1 R, 5 S)-9 \mathrm{~b}$
Figure 4. Schematic structure of the $\left[\mathrm{Ru}\left(\mathrm{P}^{*}\right)\left(\mathrm{CHCO}_{2} \mathrm{CH}_{2} \mathrm{CH}=\mathrm{CR}^{\mathrm{c}} \mathrm{R}^{\mathrm{t}}\right)\right]$ moiety in the transition states that result in formation of the lactones 9. The orientation of the carbene plane $(\mathrm{H}-\mathrm{C}-\mathrm{X})$ is based on the $\mathrm{X}$-ray structure of complex $\mathbf{3}$. Note that only the norbornane moieties at the same side as the carbene group are shown.

However, it should be noted that as $\left[\mathrm{Ru}\left(\mathrm{P}^{*}\right)\left(\mathrm{CHCO}_{2} \mathrm{CH}_{2}-\right.\right.$ $\left.\left.\mathrm{CH}=\mathrm{CR}^{\mathrm{c}} \mathrm{R}^{\mathrm{t}}\right)(\mathrm{L})\right]$ approach the transition states for the formation of lactones 9 the allyloxycarbonyl groups $\mathrm{CO}_{2} \mathrm{CH}_{2} \mathrm{CH}=\mathrm{CR}^{\mathrm{c}} \mathrm{R}^{\mathrm{t}}$ in the carbene complexes must fold to allow the $\mathrm{C}=\mathrm{C}$ bonds to be close enough to the carbene groups. This would relieve the original steric interaction between the allyl groups and respective norbornane moieties. Consequently, the carbene plane would rotate back to the position almost bisecting the angle between adjacent $\mathrm{Ru}-\mathrm{N}$ bonds (as in complex 2 ) and both of the severely tilted meso-phenyl rings would recover to their normal orientations (i.e., close to being perpendicular to the porphyrin ring). If this is the case, the $\left[\mathrm{Ru}\left(\mathrm{P}^{*}\right)\left(\mathrm{CHCO}_{2} \mathrm{CH}_{2} \mathrm{CH}=\mathrm{CR}^{\mathrm{c}} \mathrm{R}^{\mathrm{t}}\right)\right]$ moieties in the transition states should have the structure schematically shown in Figure 4.

On the basis of the indicated orientation of the carbene plane $(\mathrm{H}-\mathrm{C}-\mathrm{X})$, four possible transition states of $\left[\mathrm{Ru}\left(\mathrm{P}^{*}\right)\left(\mathrm{CHCO}_{2} \mathrm{CH}_{2}-\right.\right.$ $\left.\left.\mathrm{CH}=\mathrm{CR}^{\mathrm{c}} \mathrm{R}^{\mathrm{t}}\right)(\mathrm{L})\right]$ are to be considered, i.e., the transition states I-IV depicted in Figure $4,{ }^{45}$ which are interconvertible via rotations about the $\mathrm{C}-\mathrm{C}$ or $\mathrm{C}-\mathrm{O}$ bonds in the (allyloxycarbonyl)carbene group. The major difference between $\mathbf{I}$ and II (or between III and IV) lies in the interaction of their $\mathrm{R}^{\mathrm{c}}$ and $\mathrm{R}^{\mathrm{t}}$ groups with the norbornane moiety $\mathrm{A}$ or the interaction of the carbene methylene group directly bonded to the oxygen atom with the norbornane moiety $\mathrm{B}^{\prime} / \mathrm{B}$. Since these groups interact with the norbornane methano bridge in I and III but with the bulkier ethano bridge in II and $\mathbf{I V}$, it is expected that transition state I (or III) is more stable than transition state II (or IV).

As depicted in Figure 4, I and IV result in formation of the lactones $\mathbf{9}$ in a configuration opposite to that of $\mathbf{9}$ formed from II and III. The predominant configuration observed for 9 would depend on which of the transition states I-IV prevail in the catalytic processes.

In the cases of small $\mathrm{R}^{\mathrm{c}}$ and $\mathrm{R}^{\mathrm{t}}$ groups (such as $\mathrm{H}$ and $\mathrm{Me}$ ), I and II are apparently preferred over III and IV as a result of the smaller steric interaction between the allyloxycarbonyl group and the porphyrin ring. Because II is less stable than I, the prevailing transition state in such cases should be the latter. This is consistent with the predominant configuration observed for $\mathbf{9 a}, \mathbf{b}$ (entries 1 and 2, Table 3).

However, when $\mathrm{R}^{\mathrm{c}}$ is $\mathrm{H}$ and $\mathrm{R}^{\mathrm{t}}$ becomes a sterically demanding phenyl group ( $\mathbf{8 d}$ ), modeling studies reveal that there is an extremely severe steric interaction between the phenyl group and the porphyrin ring in I and II, and only III and IV can accommodate the phenyl group. Accordingly, the prevailing transition state for this substrate should be III (as described above, IV is less stable than III), which accounts for the predominant configuration of $(1 S, 5 R)$ found for 9d (entry 4, Table 3).

To achieve an excellent enantiocontrol, the energy difference between I and II (or between III and IV) should be sufficiently large. This requires the $\mathrm{R}^{\mathrm{c}}$ or $\mathrm{R}^{\mathrm{t}}$ groups to have a proper size so that their orientation toward the norbornane ethano bridge is effectively prohibited due to steric hindrance but their orientation toward the methano bridge experiences little strain. Evidently, $\mathrm{H}$ or Me groups are too small to meet this requirement, which rationalizes the low enantioselectivity observed for substrates $\mathbf{8 a}, \mathbf{b}$. The high enantioselectivity achieved for substrate $\mathbf{8 d}$ can be attributed to its desirably large $\mathrm{R}^{\mathrm{t}}\left(\mathrm{R}^{\mathrm{t}}=\right.$ phenyl) group, whose interaction with the norbornane methano (III) and ethano bridge (IV) resembles that depicted in Figure 3.

\section{Conclusions}

The following conclusions can be drawn from this work. First, chiral carbonyl ruthenium porphyrin $\left[\mathrm{Ru}\left(\mathrm{P}^{*}\right)(\mathrm{CO})(\mathrm{EtOH})\right](\mathbf{1})$ is one of the most trans-selective metal catalysts currently available for asymmetric intermolecular cyclopropanation of styrenes with diazoacetates $\mathrm{N}_{2} \mathrm{CHCO}_{2} \mathrm{R}$. The EDA cyclopropanation of styrene catalyzed by complex $\mathbf{1}$ affords excellent enantioselectivity with unprecedentedly high trans/cis ratio and catalyst turnovers. Second, complex 1 represents the hitherto most efficient metalloporphyrin catalyst for an asymmetric intramolecular cyclopropanation process, catalyzing the cyclopropanation of several allylic diazoacetates $\mathrm{N}_{2} \mathrm{CHCO}_{2} \mathrm{CH}_{2} \mathrm{CH}=$ $\mathrm{CR}^{\mathrm{c}} \mathrm{R}^{\mathrm{t}}$ in up to $85 \%$ ee. Third, the active intermediates in the complex 1-catalyzed inter- and intramolecular cyclopropanations could be the respective chiral electrophilic ruthenium carbene complexes $\left[\mathrm{Ru}\left(\mathrm{P}^{*}\right)(\mathrm{CHX})(\mathrm{L})\right]\left(\mathrm{X}=\mathrm{CO}_{2} \mathrm{R}, \mathrm{CO}_{2} \mathrm{CH}_{2} \mathrm{CH}=\right.$

(45) The roughly orthogonal orientation of the $\mathrm{C}=\mathrm{C}$ and $\mathrm{Ru}=\mathrm{C}$ bonds in I-IV (which contrasts with the parallel orientation in 19a,b shown in Scheme 3 for terminal alkenes) should be favored for substrates bearing nonterminal alkene moieties, such as all the allylic diazoacetates $\mathbf{8}$ examined in this work except 8a, since for the $\mathrm{C}=\mathrm{C}$ bond of a nonterminal alkene it is hard to reach a position both parallel to the $\mathrm{Ru}=\mathrm{C}$ bond and sufficiently close to the carbene $\mathrm{C}$ atom as a result of the steric interaction between the porphyrin ring and the substituents on the $\mathrm{C}=\mathrm{C}$ bond. For substrate 8a (which contains a terminal alkene moiety), the forgoing parallel orientation may be favored over any of the orientations in I-IV. If such is the case, a rationalization of the rather low enantioselectivity for $\mathbf{8 a}$ can be made on the basis of model structures shown in Figures $3 \mathrm{a}$ and $3 \mathrm{~b}$ by replacing the styrene phenyl groups in the figures with hydrogen. 
$\mathrm{CR}^{\mathrm{c}} \mathrm{R}^{\mathrm{t}}$ ), where $\mathrm{L}$ is a ligand with a considerable trans effect. Fourth, reaction of complex 1 with diazo compounds $\mathrm{N}_{2} \mathrm{CPh}_{2}$ and $\mathrm{N}_{2} \mathrm{C}(\mathrm{Ph}) \mathrm{CO}_{2} \mathrm{CH}_{2} \mathrm{CH}=\mathrm{CH}_{2}$ affords stable five-coordinate chiral ruthenium monocarbene complexes $\left[\mathrm{Ru}\left(\mathrm{P}^{*}\right)\left(\mathrm{CPh}_{2}\right)\right](2)$ and $\left[\mathrm{Ru}\left(\mathrm{P}^{*}\right)\left(\mathrm{C}(\mathrm{Ph}) \mathrm{CO}_{2} \mathrm{CH}_{2} \mathrm{CH}=\mathrm{CH}_{2}\right)\right](3)$, respectively, which constitute the first isolated chiral metalloporphyrin carbene complexes.

\section{Experimental Section}

General. All manipulations were carried out under a nitrogen atmosphere unless stated otherwise. Solvents were purified according to standard procedures. Ethyl diazoacetate (Aldrich) was used as received. The chiral $D_{4}$-symmetric Halterman's porphyrin $\left(\mathrm{H}_{2} \mathrm{P}^{*}\right),{ }^{10}$ complex $\mathbf{1},{ }^{9,46}$ allyl ${ }^{18}$ and other alkyl diazoacetates, ${ }^{2 \mathrm{~b}}$ and diphenyldiazomethane ${ }^{47}$ were prepared by the literature methods. Various alkenes purchased from Aldrich were purified by being passed through alumina or by distillation over $\mathrm{CaH}_{2} \cdot{ }^{1} \mathrm{H}$ and ${ }^{13} \mathrm{C}\left\{{ }^{1} \mathrm{H}\right\}$ NMR spectra were recorded on a Bruker DPX-300 or DRX-500 FT-NMR spectrometer. Chemical shifts were referenced to tetramethylsilane. Fast atom bombardment (FAB) mass spectra were obtained on a Finnigan MAT 95 mass spectrometer with 3-nitrobenzyl alcohol as the matrix. UVvisible spectra were recorded on a Perkin-Elmer Lambda 19 spectrophotometer. GC-MS measurements were performed on a HP G1800C GCD Series II spectrometer. Elemental analyses were performed by the Butterworth Laboratories Ltd., Teddington, UK.

Preparation of $\left[\mathbf{R u}\left(\mathbf{P}^{*}\right)\left(\mathbf{C P h}_{2}\right)\right]$ (2). A solution of diphenyldiazomethane $(20 \mathrm{mg}, 0.10 \mathrm{mmol})$ in benzene $(15 \mathrm{~mL})$ was added to a solution of complex 1 ( $50 \mathrm{mg}, 0.038 \mathrm{mmol})$ in benzene $(15 \mathrm{~mL})$ under an argon atmosphere. The resulting mixture was stirred for $3 \mathrm{~h}$. After removal of all the volatiles in vacuo, the product was extracted into $n$-pentane and the filtrate was evaporated to dryness. The residue was then recrystallized from dichloromethane/acetonitrile and dried in vacuo. Yield: $86 \%$. Anal. Calcd for $\mathrm{C}_{97} \mathrm{H}_{86} \mathrm{~N}_{4} \mathrm{Ru}$ : C, 82.70; H, 6.15; N, 3.98. Found C, 82.99; H, 6.34; N, 3.72. ${ }^{1} \mathrm{H}$ NMR $\left(500 \mathrm{MHz}, \mathrm{CDCl}_{3}\right.$. For labeling of various protons, see Figure $\mathrm{S} 2): \delta \mathrm{H}_{\beta} 8.26(\mathrm{~m}, 8 \mathrm{H}), \mathrm{H}_{\mathrm{p}}{ }^{\prime}$ 7.28 (s, 4H), $\mathrm{H}_{\mathrm{a}}, \mathrm{H}_{\mathrm{a}}{ }^{\prime}, \mathrm{H}_{\mathrm{b}}, \mathrm{H}_{\mathrm{b}}{ }^{\prime} 3.57$ (d, 4H), 3.47 (d, 4H), 2.89 (d, 4H), 2.39 (d, 4H), $\mathrm{CH}_{2} 0.79-2.04(\mathrm{~m}, 48 \mathrm{H}) ; \mathrm{CPh}_{2}: \mathrm{H}_{\mathrm{p}} 6.32(\mathrm{t}, 2 \mathrm{H}), \mathrm{H}_{\mathrm{m}}$ $6.11(\mathrm{t}, 4 \mathrm{H}), \mathrm{H}_{\mathrm{o}} 3.41(\mathrm{~d}, 4 \mathrm{H}) .{ }^{13} \mathrm{C} \mathrm{NMR}\left(300 \mathrm{MHz}, \mathrm{CDCl}_{3}\right): \delta 315$ $(\mathrm{Ru}=C) . \mathrm{UV} / \mathrm{vis}\left(7.54 \times 10^{-6} \mathrm{M}, \mathrm{CH}_{2} \mathrm{Cl}_{2}\right): \lambda_{\max }(\log \epsilon) 397$ (5.19), 432 (5.06), $536 \mathrm{~nm}$ (4.29). FAB-MS: $\mathrm{m} / z, 1409\left(\mathrm{M}^{+}\right)$.

Preparation of $\left[\mathrm{Ru}\left(\mathrm{P}^{*}\right)\left(\mathrm{C}(\mathrm{Ph}) \mathrm{CO}_{2} \mathrm{CH}_{2} \mathbf{C H}=\mathrm{CH}_{2}\right)\right](3)$. To an ice bath-cooled solution of complex $1(50 \mathrm{mg}, 0.038 \mathrm{mmol})$ in dichloromethane $(5 \mathrm{~mL})$ under argon was added a solution of allyl $\alpha$-diazophenylacetate $(40 \mathrm{mg}, 0.20 \mathrm{mmol})$ in dichloromethane $(10 \mathrm{~mL})$ by syringe over $10 \mathrm{~h}$. The reaction mixture was then treated with methanol $(2 \mathrm{~mL})$ and evaporated to dryness under vacuum at room temperature. Column chromatography of the residue on basic alumina with dichloromethane/hexane $(1: 5 \mathrm{v} / \mathrm{v})$ as eluent gave the desired product as a dark red solid in $85 \%$ yield. Anal. Calcd for $\mathrm{C}_{95} \mathrm{H}_{86} \mathrm{~N}_{4} \mathrm{O}_{2} \mathrm{Ru} \cdot \mathrm{MeOH}$ : C, 79.58; H, 6.26; N, 3.87. Found C, 79.85; H, 6.09; N, 4.08. ${ }^{1} \mathrm{H}$ NMR $\left(500 \mathrm{MHz}, \mathrm{CDCl}_{3}\right.$. For labeling of various protons, see Figure $\mathrm{S} 3$ ): $\delta$ $\mathrm{H}_{\beta} 8.35(\mathrm{~m}, 8 \mathrm{H}), \mathrm{H}_{\mathrm{p}}{ }^{\prime} 7.30(\mathrm{~s}, 4 \mathrm{H}), \mathrm{H}_{\mathrm{a}}, \mathrm{H}_{\mathrm{a}}{ }^{\prime}, \mathrm{H}_{\mathrm{b}}, \mathrm{H}_{\mathrm{b}}{ }^{\prime} 3.56(\mathrm{~d}, 4 \mathrm{H}), 3.48$ $(\mathrm{d}, 4 \mathrm{H}), 3.11(\mathrm{~d}, 4 \mathrm{H}), 2.43(\mathrm{~d}, 4 \mathrm{H}), \mathrm{CH}_{2} 0.87-2.02(\mathrm{~m})$; carbene Ph: $\mathrm{H}_{\mathrm{p}} 6.59(\mathrm{t}, 1 \mathrm{H}), \mathrm{H}_{\mathrm{m}} 6.16(\mathrm{t}, 2 \mathrm{H}), \mathrm{H}_{\mathrm{o}} 3.70(\mathrm{~d}, 2 \mathrm{H}) ; \mathrm{CO}_{2} \mathrm{CH}_{2} \mathrm{CH}=$ $\mathrm{CH}_{2}$ : $\mathrm{CH} 4.92(\mathrm{~m}, 1 \mathrm{H}), \mathrm{CH}=\mathrm{CH}_{2} 4.49(\mathrm{~d}, 1 \mathrm{H}), 4.28(\mathrm{~d}, 1 \mathrm{H}), \mathrm{OCH}_{2}$ $3.38(\mathrm{dd}, 1 \mathrm{H}), \sim 3.1(\mathrm{dd}, 1 \mathrm{H}$, note that only one of the two doublets is discernible owing to a partial overlap of this signal with the intense

(46) (a) Berkessel, A.; Frauenkron, M. J. Chem. Soc., Perkin Trans. 1 1997, 2265. (b) Lai, T.-S.; Kwong, H.-L.; Zhang, R.; Che, C.-M. J. Chem. Soc., Dalton Trans. 1998, 3559.

(47) Miller, J. B. J. Org. Chem. 1959, 24, 560. signal at $\delta 3.11) .{ }^{13} \mathrm{C} \mathrm{NMR}\left(300 \mathrm{MHz}, \mathrm{CDCl}_{3}\right): \delta 285(\mathrm{Ru}=C) . \mathrm{UV} /$ vis $\left(6.08 \times 10^{-6} \mathrm{M}, \mathrm{CH}_{2} \mathrm{Cl}_{2}\right): \lambda_{\max }(\log \epsilon) 402$ (5.26), $442 \mathrm{sh}$ (4.72), $533 \mathrm{~nm}$ (4.20). FAB-MS: $m / z, 1417\left(\mathbf{M}^{+}\right)$.

Intermolecular Cyclopropanation Catalyzed by Complexes 1 and 2. A Typical Procedure. A solution of complex 1 ( $3.3 \mathrm{mg}, 2.5 \mu \mathrm{mol})$ and styrene $(2.65 \mathrm{~g}, 25 \mathrm{mmol})$ in dichloromethane $(10 \mathrm{~mL})$ was stirred at room temperature for $30 \mathrm{~min}$. EDA $(0.57 \mathrm{~g}, 5.0 \mathrm{mmol})$ was added via a syringe pump over $8 \mathrm{~h}$, and the mixture was stirred for an additional $12 \mathrm{~h}$. The trans/cis ratio was determined by GC-MS with an Ultra 2 cross-linked 5\% phenyl-methyl silicone column $(25 \mathrm{~m} \times 0.2$ $\mathrm{mm} \times 0.33 \mu \mathrm{m})$. After the desired products were purified by flash chromatography, their enantiomeric excesses were determined by chiral GC with a Cyclodex B column (J \& W Scientific, $30 \mathrm{~m}$ ) or chiral HPLC with a Daicel OJ column.

Competitive Cyclopropanations Catalyzed by Complex 1. In a typical experiment, equimolar amounts of each alkene ( $1.5 \mathrm{mmol}$ each) and complex $1(0.5 \mathrm{mg})$ were dissolved in dichloromethane $(2 \mathrm{~mL})$ at room temperature. A solution of EDA $(0.3 \mathrm{mmol})$ in dichloromethane $(1 \mathrm{~mL})$ was added over a period of $6 \mathrm{~h}$. The cyclopropyl esters formed were analyzed by GC-MS.

Intramolecular Cyclopropanation Catalyzed by Complex 1. To a well-stirred solution of complex $1(2.2 \mathrm{mg}, 0.0017 \mathrm{mmol})$ in $\mathrm{CH}_{2} \mathrm{Cl}_{2}$ $(2 \mathrm{~mL})$ was added dropwise allylic diazoacetate $(0.25 \mathrm{mmol})$ in $\mathrm{CH}_{2-}$ $\mathrm{Cl}_{2}(2 \mathrm{~mL})$ at room temperature. The reaction mixture was stirred for $18 \mathrm{~h}$. The desired products were purified by flash column chromatography with a suitable mixture of ethyl acetate and petroleum ether (bp $40-60{ }^{\circ} \mathrm{C}$ ) as the eluent.

$\mathrm{X}$-ray Crystal Structure Determination of $\mathbf{2} \cdot 2 \mathrm{CH}_{2} \mathrm{Cl}_{2}$ and 3 . $\mathbf{3} \mathrm{CH}_{2} \mathbf{C l}_{2}$. Single crystals of $\mathbf{2} \cdot 2 \mathrm{CH}_{2} \mathrm{Cl}_{2}$ and $\mathbf{3} \cdot 3 \mathrm{CH}_{2} \mathrm{Cl}_{2}$ were obtained from slow evaporation of a solution of $\mathbf{2}$ in dichloromethane/acetonitrile at $-20{ }^{\circ} \mathrm{C}$ and a solution of $\mathbf{3}$ in dichloromethane/hexane at $5{ }^{\circ} \mathrm{C}$. For $2 \cdot 2 \mathrm{CH}_{2} \mathrm{Cl}_{2}$, a crystal of the dimensions $0.40 \times 0.20 \times 0.05 \mathrm{~mm}$ was mounted on a glass fiber and diffraction data were collected in the $\theta$ range of $1.23-27.49^{\circ}$ at $295(2) \mathrm{K}$ on a Siemens SMART CCD diffractometer; for $3 \cdot 3 \mathrm{CH}_{2} \mathrm{Cl}_{2}$, a crystal of the dimensions $0.20 \times 0.16$ $\times 0.14 \mathrm{~mm}$ was mounted on a glass fiber and diffraction data were collected in the $\theta$ range of $1.67-27.60^{\circ}$ at $294(2) \mathrm{K}$ on a Bruker SMART CCD diffractometer. In both cases, graphite monochromatized Mo K $\alpha$ radiation $\left(\lambda=0.71073 \AA\right.$ ) was used. The structures of $2 \cdot 2 \mathrm{CH}_{2-}$ $\mathrm{Cl}_{2}$ and $3 \cdot 3 \mathrm{CH}_{2} \mathrm{Cl}_{2}$ were solved by the heavy atom method and refined by full-matrix least squares on $F^{2}$ by using the SHELXL programs.

Acknowledgment. This work was supported by The University of Hong Kong, the Hong Kong Research Grants Council, the Hong Kong University Foundation, and the Croucher Foundation.

Supporting Information Available: Results of complex 1-catalyzed cyclopropanation of styrene with EDA in various solvents (Table $\mathrm{S} 1), \log \left(k_{\mathrm{X}} / k_{\mathrm{H}}\right)$ vs $\sigma^{+}$plot for complex 1-catalyzed cyclopropanation of para-substituted styrenes (Figure S1), ${ }^{1} \mathrm{H}$ NMR spectra of complexes $\mathbf{2}$ and $\mathbf{3}$ in $\mathrm{CDCl}_{3}$ (Figures S2 and S3), and side views of the structure of complex $\mathbf{2}$ (Figure S4), along with ORTEP drawings with the atom-numbering schemes, tables of final coordinates, bond lengths, bond angles, and anisotropic displacement parameters of $2 \cdot 2 \mathrm{CH}_{2} \mathrm{Cl}_{2}$ and $3 \cdot 3 \mathrm{CH}_{2} \mathrm{Cl}_{2}$ (PDF). This material is available free of charge via the Internet at http://pubs.acs.org.

JA001416F 